NBER WORKING PAPER SERIES

\title{
HEALTH INSURANCE AND MORTALITY: \\ EXPERIMENTAL EVIDENCE FROM TAXPAYER OUTREACH
}

\author{
Jacob Goldin \\ Ithai Z. Lurie \\ Janet McCubbin \\ Working Paper 26533 \\ http://www.nber.org/papers/w26533 \\ NATIONAL BUREAU OF ECONOMIC RESEARCH \\ 1050 Massachusetts Avenue \\ Cambridge, MA 02138 \\ December 2019
}

Goldin: Stanford University and NBER. Lurie: Office of Tax Analysis, U.S. Department of the Treasury. McCubbin: Office of Tax Analysis, U.S. Department of the Treasury. For helpful comments, we are grateful to Marianne Bitler, Mark Duggan, Amy Finkelstein, Alex Gelber, Jon Gruber, Dan Ho, Tatiana Homonoff, Jason Levitis, Adam Looney, Dan Kessler, Jonathan Ketcham, Amanda Kowalski, Michelle Mello, Ankur Patel, Paul Reyfman, Kyle Rozema, Dan Sacks, Deborah Schwartz, David Studdert, and seminar participants at Berkeley, George Mason, Max Planck Institute, Stanford, Treasury, the Annual Health Economics Conference, the NTA Annual Conference, and the WEAI Annual Conference. For implementation assistance, we thank Debra Babcock, Jason Levitis, Pedro Mendez, Lina Rashid, Elana Safran, Carolyn Tavenner, and Christen Linke Young. Taylor Cranor, Sarah Kotb, and Vedant Vohra provided outstanding research assistance. The views and opinions expressed in this paper are those of the authors and do not necessarily represent the position of the Treasury Department or any agency of the United States. This paper was reviewed by the Treasury Department prior to release to ensure compliance with rules governing the confidentiality of taxpayer return information. The views expressed herein are those of the authors and do not necessarily reflect the views of the National Bureau of Economic Research.

NBER working papers are circulated for discussion and comment purposes. They have not been peer-reviewed or been subject to the review by the NBER Board of Directors that accompanies official NBER publications.

(C) 2019 by Jacob Goldin, Ithai Z. Lurie, and Janet McCubbin. All rights reserved. Short sections of text, not to exceed two paragraphs, may be quoted without explicit permission provided that full credit, including $\odot$ notice, is given to the source. 
Health Insurance and Mortality: Experimental Evidence from Taxpayer Outreach

Jacob Goldin, Ithai Z. Lurie, and Janet McCubbin

NBER Working Paper No. 26533

December 2019

JEL No. H2,I12,I13

\section{ABSTRACT}

We evaluate a randomized pilot study in which the IRS sent informational letters to 3.9 million taxpayers who paid a tax penalty for lacking health insurance coverage under the Affordable Care Act. Drawing on administrative data, we study the effect of the intervention on taxpayers' subsequent health insurance enrollment and mortality. We find the intervention led to increased coverage in the two years following treatment and that this additional coverage reduced mortality among middle-aged adults over the same time period. Our results provide the first experimental evidence that health insurance reduces mortality.

Jacob Goldin

Stanford Law School

559 Nathan Abbott Way

Stanford, CA 94305

and NBER

jsgoldin@law.stanford.edu

Ithai Z. Lurie

Department of the Treasury

1500 Pennsylvania Avenue NW

Washington, DC 20220

Ithai.Lurie@treasury.gov
Janet McCubbin

U.S. Department of the Treasury

Janet.McCubbin@treasury.gov 


\section{Introduction}

Near the beginning of 2017, the Internal Revenue Service (IRS) sent informational letters to taxpayers who had previously paid an income tax penalty for lacking health insurance coverage under the so-called individual mandate provision of the Affordable Care Act (ACA). ${ }^{1}$ Of the 4.5 million households who met the criteria for inclusion in this pilot program, 3.9 million were randomly selected to receive the intervention. In this paper, we exploit the pilot's randomized design to study the operation of tax-based incentives for promoting health insurance take-up. Because the pilot led to increased coverage, we also use it to explore the causal relationship between health insurance and mortality.

Reducing the share of uninsured Americans has been an important goal of U.S. domestic policy for decades, but substantial controversy still exists over which policies are effective at achieving this objective. For example, some have criticized the individual mandate as being too small or too non-salient to effectively induce taxpayers to increase their coverage (Auerbach et al., 2010). Partly in response to such concerns, the federal government, states, and non-profits spend hundreds of millions of dollars each year on outreach efforts to bolster the incentive effect of policies like the individual mandate. ${ }^{2}$ By linking the IRS pilot to administrative micro-data on health insurance coverage, we can shed light on these concerns and on the potential for outreach programs to alleviate them. Although the individual mandate is now effectively repealed at the federal level, exploring these issues is important for assessing proposals to impose (or re-impose) an individual mandate at the state or federal level (Levitis, 2018) and for informing outreach efforts (Dorn, 2019).

The second question we use the pilot to investigate is the effect of health insurance on mortality. Although this question is among the most widely studied question in health economics, it is notoriously difficult to answer in credible ways. ${ }^{3}$ Theoretically, the magnitude and even existence of an effect is ambiguous - for example, uninsured individuals with acute life-threatening conditions may still seek and obtain emergency care, which most hospitals in the United States are legally required to provide (Newhouse et al., 1993; Finkelstein and McKnight, 2008; Black et al., 2019). Similarly, because of adverse selection, individuals who choose to forego coverage to which they have access may be particularly unlikely to benefit if induced to enroll. Empirically, a growing number of well-designed quasi-experimental studies suggest that health insurance does substantially

\footnotetext{
${ }^{1}$ From 2014 to 2018 , federal law required most individuals to enroll in health insurance coverage or pay a tax penalty. As with other taxes, the Internal Revenue Service (IRS) played a central role administering this provision, including explaining its operation to taxpayers.

${ }^{2}$ Federal funding for ACA-related outreach has fluctuated in recent years, with the budgeted amount for ACA advertising declining from $\$ 100$ million in 2017 to $\$ 10$ million in 2018 . However, states and non-profits have continued to fund coverage-related outreach efforts at high levels - e.g., California's 2018 budget for Navigator programs was $\$ 111$ million (Commonwealth Fund, 2017).

${ }^{3}$ The issue is also disputed among policymakers, some of whom have expressed skepticism about whether health insurance reduces mortality (Phillips, 2017).
} 
reduce adult mortality in certain contexts (Card, Dobkin and Maestas, 2009; Sommers, Baicker and Epstein, 2012; Sommers, Long and Baicker, 2014; Swaminathan et al., 2018; Khatana et al., 2019; Borgschulte and Vogler, 2019; Miller et al., 2019), ${ }^{4}$ but the results that emerge from these studies rely on unverifiable and sometimes controversial assumptions (Levy and Meltzer, 2008; Woolhandler and Himmelstein, 2017; Black et al., 2019). Prior randomized studies on this question are rare and inconclusive, both in the United States (Finkelstein et al. 2012 ("the Oregon study"); Weathers and Stegman 2012) and worldwide. ${ }^{5}$ In addition, prior research - whether observational or experimental - focuses on the health effects from expanded access to coverage, not from changes in enrollment behavior with respect to coverage that was already available. Understanding the effects of the latter type of intervention - our focus here - is important for assessing the health benefits from outreach efforts of the type commonly undertaken by governments and non-profits.

Our results provide evidence that the intervention increased the likelihood of taxpayers obtaining coverage, and that this additional coverage reduced middle-age mortality during the two years following the intervention. Beginning with the effect on coverage, we find that among individuals who were uninsured for some portion of the prior year, those in the treatment group were 1.3 percentage points more likely to enroll in coverage in the year following the intervention than those in the control group, a $2.8 \%$ relative increase. On average, each letter increased coverage among this group by 0.14 months during 2017, or one additional year of coverage per 87 letters sent. We document larger effects among individuals who lacked any coverage during the prior year and among older nonelderly adults. The effect appears to operate through new enrollments in the individual marketplace as well as through Medicaid take-up. Although there is some attenuation, coverage rates remains higher in the treatment group than in the control group in the two years following the intervention.

In the second part of the paper, we study whether the additional coverage induced by the intervention reduced mortality among those who enrolled. We present evidence that it did. In the two years following the intervention, the rate of mortality among previously uninsured 45-64 year-olds was lower in the treatment group than in the control by approximately 0.06 percentage points, or one fewer death for every 1,648 individuals in this population who were sent a letter. We find no evidence that the intervention reduced mortality among children or younger adults over our sample period. Exploiting

\footnotetext{
${ }^{4} \mathrm{~A}$ separate body of quasi-experimental evidence finds that child health coverage yields health benefits (Currie and Gruber, 1996a,b; Meyer and Wherry, 2012; Goodman-Bacon, 2018; Brown, Kowalski and Lurie, Forthcoming).

${ }^{5}$ Newhouse et al. (1993) reports experimental evidence that health insurance can reduce mortality but the intervention they study consists of variation in cost-sharing rather than the presence or absence of coverage itself. Escobar, Griffin and Shaw (2011) and Giedion, Alfonso and Diaz (2013) survey international evidence on the link between health insurance and mortality and do not report the existence of any randomized studies.
} 
treatment group assignment as an instrument for coverage, we estimate that the average per-month effect of the coverage induced by the intervention on two-year mortality was approximately -0.17 percentage points. We caution, however, that the magnitude of the mortality effect is imprecisely estimated; our confidence interval is consistent with both moderate and large effects of coverage on mortality. At the same time, our estimated confidence interval is sufficiently precise to rule out per-month effects smaller in magnitude than -0.03 percentage points, including the estimate from the OLS regression of mortality on coverage across individuals. We view the effects at the lower-magnitude end of our confidence interval as most plausible, given the treatment effect magnitudes reported in prior research (see Black et al., 2019, for a review). We also present suggestive evidence that the steady-state effect of annual coverage on mortality is less than 12 times our estimated per-month effect due to concavity in the relationship between coverage and mortality. With these caveats, our results provide the first experimental evidence that health insurance reduces mortality.

Our results contribute to important literatures in public finance and health economics. First, a number of studies investigate the effect of policies like the individual mandate that are designed to incentivize health insurance coverage (e.g., Buchmueller, DiNardo and Valletta, 2011; Phillip, McKnight and Heep, 2011; Hackmann, Kolstad and Kowalski, 2015; Frean, Gruber and Sommers, 2017; Finkelstein, Hendren and Shepard, 2017; Heim, Lurie and Sacks, 2019). Our findings provide experimental evidence that informational frictions like low salience or complexity can limit the effectiveness of such policies (if not, our intervention would not have had an effect). In this sense, our results complement recent studies that document mistakes in other domains of health-related decisions (Abaluck and Gruber, 2011; Handel, 2013; Handel and Kolstad, 2015; Handel, Kolstad and Spinnewijn, 2018; Chandra, Handel and Schwartzstein, 2018; Loewenstein et al., 2013). In a different vein, some have suggested that the dollar value of the federal mandate penalty may have been too small to influence behavior (Auerbach et al., 2010; Frean, Gruber and Sommers, 2016); our coverage results provide evidence against that view, at least with respect to the 2017 federal penalty. By shedding light on these issues, our results can inform states that have implemented state-level substitutes after the federal mandate's repeal, or that are considering doing so.

Second, our results provide new evidence on a central question in health economics: the link between health insurance and mortality. The question is hotly debated, and prior studies have come to differing conclusions. ${ }^{6}$ Because our design is randomized, it is not subject to most of the identification concerns that have been leveled against observational studies in this area. In addition, our study complements the prior experimental evidence in important ways. Because mortality is a rare event, statistical power poses a significant

\footnotetext{
${ }^{6}$ For two prominent examples, compare the findings of the Institute of Medicine's 2002 Consensus Report with Kronick (2009).
} 
concern for both experimental and non-experimental analyses of the topic. The size of our sample permits us to restrict our main mortality analysis to older adults, a population for which the protective effects of coverage on mortality is more likely to be detectable. In addition, the group for which we identify the health effect of coverage - i.e., those who already have access to coverage but for whom misperceptions or other frictions prevent take-up - is particularly policy relevant, since such individuals' coverage decisions can be shaped through outreach efforts of the type commonly employed by governments and non-profits. Indeed, our experimental sample represents the near-universe of uninsured individuals who are the typical targets of such policy efforts.

Methodologically, our analysis illustrates how large-scale field experiments can provide information not only about the intervention being studied, but also about downstream effects of the behavior that the intervention induces. In particular, health insurance access is expensive to provide, but absent randomization, credible estimates of the effect of health insurance on health are difficult to obtain. By exploiting a pilot study that randomly encouraged individuals to take up coverage that was already available to them, our approach represents a cost-effective and ethical method for studying the effect of coverage on subsequent health outcomes.

Finally, we highlight a new resource for studying health insurance in the United States: information returns about individual coverage reported to the IRS. Prior research on this topic has mostly relied on self-reported survey data for a small fraction of the population or administrative coverage data obtained from a single insurer. Our dataset offer several important advantages. First, it covers the near-universe of individuals living in the United States, which limits concerns about selection and endogenous sample retention. Second, because the data contain individual-level coverage information from multiple insurers, it allows us to observe flows between insurance providers or types of insurance. Third, the monthly frequency of our data allows us to more precisely quantify the first-stage effects of interventions like the one we study and the dynamics of treatment effects over time. Because most prior studies have lacked such precise measures of coverage, they have typically focused on a binary indicator for being enrolled in any coverage at a single point in time, which can bias instrumental variable estimation when the treatment affects coverage on other margins.

The remainder of the article proceeds as follows. Section 2 provides institutional background on health insurance coverage in the United States and the federal individual mandate. Section 3 describes our research design and provides information about our data, the pilot study, and summary statistics. Section 4 analyzes the effect of the intervention on coverage. Section 5 contains the mortality analysis. Section 6 concludes. 


\section{Institutional Background}

\subsection{Health Insurance Coverage in the United States}

Most people in the United States with health insurance have coverage from their employer (employer-sponsored insurance, or ESI). The second largest source of health insurance is through a government program such as Medicaid, Medicare, or the Veteran's Administration. Individuals who do not receive health insurance from one of these sources may enroll in an "Exchange" plan, purchased through their state's health insurance marketplace, or in an "Off-Exchange" plan.

To understand how the pilot affected coverage decisions, it is helpful to understand the regulatory constraints on the timing of health insurance enrollment. Unless special circumstances apply, ${ }^{7}$ one may enroll in Exchange coverage for the year only during the year's open enrollment period. For 2017 Exchange coverage, the open enrollment window was from November 1, 2016 to January 31, 2017. In addition, individuals are required to apply for Exchange coverage by the 15th day of the month prior to the month in which coverage is to begin. Thus, to obtain coverage for January 2017, individuals must have applied by December 15, 2016; to obtain coverage for February 2017, individuals must have applied by January 15, 2017. Most employer-sponsored plans also have an annual open enrollment period to enroll in coverage for the year, often ending a month or two prior to the end of the calendar year (although the timing varies). In contrast, individuals can obtain Medicaid coverage at any time during the year (e.g., during a hospitalization), and Medicaid coverage can apply retroactively for up to three months prior to the month of application.

Most individuals apply for Exchange coverage through an online portal. States may rely on the federal marketplace or operate their own state-based marketplace. Individuals who visit the federal online portal, healthcare.gov, are routed to the applicable marketplace based on their location. To determine the after-subsidy cost of Exchange coverage, individuals who visit the Exchange input information about their family size and income. If the household qualifies for Medicaid, they can enroll in that coverage through the website as well.

In recent years, the share of Americans under the age of 65 who lack health insurance coverage for the entire year is approximately $9 \%-13 \%$, depending on the source of the estimate. ${ }^{8}$ The share of Americans who lack coverage for one month or more during the year is much higher, approximately $21 \%$ to $26 \%$, depending on the estimate. Among those with full-year coverage in 2016, $65 \%$ received at least one month of coverage from

\footnotetext{
${ }^{7}$ Examples of life events that qualify an individual to enroll in coverage outside of the standard open enrollment window include losing health coverage (e.g., by losing one's job), getting married or divorced, or the birth of a new child.

${ }^{8}$ The statistics cited in this paragraph are reported in Lurie and Pearce (2019).
} 
their employer. An additional 35\% received at least one month of government-provided coverage (e.g., Medicaid or coverage provided by the Veteran's Administration). Finally, $10 \%$ of those with full-year coverage were enrolled in at least one month of non-group coverage (i.e., from an Exchange or off-Exchange plan).

Increasing the share of Americans with health insurance coverage has been a longterm policy goal of U.S. tax and health policy-making. A range of tax provisions support this objective, such as the income and payroll tax exclusion for employer-provided health insurance, the premium tax credit, the employer mandate, and the individual mandate the policy that is the focus of our intervention.

\subsection{The Individual Mandate}

The Shared Responsibility Payment provision of the Patient Protection and Affordable Care Act (ACA), or the individual mandate, as it is commonly referred to, requires most individuals to obtain health insurance coverage for themselves and their dependents or pay a penalty in the form of a tax. The goal of the provision was to reduce the rate of uninsured Americans and reduce adverse selection in the Exchanges. Preventing adverse selection is particularly important for the viability of the Exchanges because the ACA prohibited insurers from denying or limiting coverage based on preexisting conditions.

Individuals who lack qualifying health insurance coverage for themselves or a dependent for one or more months during the year owe an additional amount on their annual income tax return - the so-called penalty - unless an exemption applies. Exemptions are available under a range of circumstances; they include: unaffordability of the available coverage to the individual, income below the income tax filing threshold, general hardship, individuals living abroad, gaps in coverage of three months or less, and religious

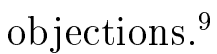

The amount of the annual penalty owed by a taxpayer depends on the taxpayer's income, family size, and number of months without coverage. The specific parameters vary by year, but in 2017 (our first year of focus), the penalty for taxpayer $i$ for month $m, P_{i m}$, is given by:

$$
P_{i m}=\frac{1}{12} \max \left\{\min \left\{695 A_{i}+347.5 C_{i}, 2085\right\}, 0.025\left(I_{i}-F_{i}\right)\right\}
$$

where $A_{i}$ is the number of adults on $i$ 's return, $C_{i}$ is the number of children, $F_{i}$ is the applicable filing threshold for taxpayer $i$, and $I_{i}$ is a measure of i's income during the tax year. ${ }^{10}$ In turn, $i$ 's annual penalty, $P_{i}$, is the sum of $i$ 's monthly penalties, limited by the yearly premium for the national average lowest cost bronze plan that would be available

\footnotetext{
${ }^{9}$ For additional details, refer to Lurie and McCubbin (2016).

${ }^{10}$ Specifically, $I_{i}$ refers to modified adjusted gross income, which for purposes of the individual mandate is defined as adjusted gross income plus untaxed foreign income and tax-exempt interest.
} 
to $i$ 's household $\left(L C B P_{i}\right)$ :

$$
P_{i}=\min \left\{\Sigma_{m=1}^{12} P_{i m}, L C B P_{i}\right\}
$$

In December of 2017, the President signed the Tax Cuts and Jobs Act, which among other changes to the tax code, effectively eliminated the individual mandate for 2019 and onward. In response, a number of states have enacted, or are considering enacting, legislation at the state-level that would resemble the operation of the federal individual mandate. To date, California, New Jersey, Rhode Island, and Washington, D.C. have already enacted such legislation. In addition, Massachusetts adopted an individual mandate as part of its 2006 health reform, and it remains in effect today (see Levitis, 2018).

Even while the federal mandate was in effect, a number of elements in its design may have limited its effect on individuals' coverage decisions. ${ }^{11}$ First, some individuals may have neglected to consider the penalty when deciding whether to enroll in coverage, either because the penalty was not salient or because they lacked knowledge of its existence (Chetty, Looney and Kroft, 2009). Because the penalty appears as a single line on one's tax return, even those who paid it may not have learned of its existence, especially if they used software or a third party to prepare their tax return. Second, the penalty formula is quite complex (as described above, it is the minimum of a maximum of a minimum). Complex incentives may yield weaker behavioral effects than when the incentive is simple (Abeler and Jäger, 2015). Third, the timing of the mandate's penalty may render it less effective (Gallagher and Muehlegger, 2011). Even if the penalty is salient to individuals when they pay their taxes (typically February through April), they may forget about it by the close of the calendar year when the next open enrollment window begins. These elements of the mandate's design motivated the IRS pilot study.

\section{Data and Research Design}

This section describes our data, the experimental sample, the intervention we study, and provides summary statistics and balance checks relating to our sample population.

\subsection{Data Sources}

For our analysis, we rely on administrative records from population files housed at the Internal Revenue Service (IRS). These data include annual information on the universe of individuals who file or are listed on individual tax returns, as well as annual and sub-annual information on the universe of individuals listed on information returns.

\footnotetext{
${ }^{11}$ Separately, some have suggested that the penalty amount was too low to motivate individuals to obtain coverage.
} 
Our health insurance coverage data are derived from information returns (Form 1095 A/B/C), which provide monthly coverage information at the individual level. The forms are provided annually to the IRS by private and public insurers, self-insured employers, and health insurance marketplaces. In addition to allowing us to identify whether an individual is covered during a particular month, the data provide information about the type of coverage in which the individual is enrolled (e.g., Medicaid, Employer-Sponsored Insurance (ESI), or individual coverage purchased through an Exchange).

Only certain forms of health insurance, referred to as minimum essential coverage (MEC), satisfy the individual mandate. These are the only forms of coverage reported on the Form 1095's. Examples of health insurance plans that do not constitute MEC include plans limited to vision or dental care, workers' compensation, or coverage that is limited to a specific disease or condition. For additional details about the coverage data on which we rely, refer to Lurie and Pearce (2019).

Our measure of health insurance coverage is available monthly from January 2015 through December 2018. We assume that individuals for whom no Form 1095 is received for a year are uninsured during each month of that year.

Our data on mortality comes from the Social Security Death File, which records the universe of U.S. deaths along with the date at which the death occurred. Our analysis includes deaths that occurred through December 2018. Unfortunately, the data do not contain information about the cause of death.

\subsection{Sample Construction}

To construct our sample, we first identified tax returns for 2015 that reported owing a positive penalty under the individual mandate. Approximately 6.1 million 2015 tax returns fell into this category. ${ }^{12}$ For context, in the same year, the total number of tax returns filed was approximately 140 million, of which 22.8 million did not indicate full-year coverage for each household member (i.e., each individual listed on the tax return). ${ }^{13}$

We next excluded returns that satisfied one or more of the following conditions: the taxpayer was claimed as a dependent; the filing address was not from one of the 50 U.S. states or D.C.; the taxpayer filed multiple (non-amended) 2015 returns; the filing address listed a second address line (typically "C/O"); the return listed an Individual Taxpayer Identification Number for a taxpayer or dependent; the taxpayer was over age 64 or under

\footnotetext{
${ }^{12}$ This figure refers to the 2015 tax returns that had been filed and posted on the IRS system as of October 2016, when the sample was constructed. Some additional 2015 tax returns were filed after that date, and other previously filed 2015 returns were amended.

${ }^{13}$ Among those tax returns that did not indicate full-year coverage for each household member and that did not report owing a penalty, approximately 11.3 million claimed an exemption for one or more months of the year. Among the remaining approximately 5.4 million returns, some reported a penalty but filed after our sample was constructed whereas others failed to either claim an exemption or report a penalty.
} 
age 18 at the start of 2017; the taxpayer was observed to die prior to the date of sample construction; the taxpayer's account was subject to certain audit or examination codes; and a household member listed on the return was observed to have enrolled in Exchange Coverage either in 2015 or in 2016 prior to our sample being finalized. As discussed further below, every individual listed on a return is included in our analysis: the primary taxpayer, the spouse if married and filing jointly, as well as up to four dependents. The final sample consists of 4.5 million returns, corresponding to 8.9 million individuals.

\subsection{Pilot Study}

The pilot intervention we study took the form of an informational letter sent to taxpayers from the IRS. The letter informed recipients that they had paid a penalty in 2015; provided information about the penalty and plan costs for 2017; and provided instructions for recipients to investigate the availability of Exchange and Medicaid coverage through healthcare.gov. A sample letter is provided in Appendix Figure A.1. Individuals in the sample were randomly assigned to receive a letter (86\%) or to a control group (14\%). One letter, addressed to the taxpayer(s), was sent per return. Hence, randomization was conducted at the household level. ${ }^{14}$

The treatment arms varied in either the content or the timing of the intervention. Households selected to receive a letter were randomly assigned across several treatment arms. We explore differences in coverage effects across treatment variants in a companion paper, so provide only a high-level overview here. The baseline treatment contained a personalized estimate of the taxpayer's potential 2017 penalty (based on 2015 income and household composition) and was mailed in mid-January 2017, approximately two weeks before the close of the open enrollment period. A "non-personalized" treatment variant was identical to the baseline treatment except that the letter provided generic information about the 2017 penalty formula rather than a personalized estimate. An "exemption information" treatment variant was identical to the baseline treatment, but included additional information about penalty exemptions for which the taxpayer might apply. An "early mailing" treatment variant was identical in content to the baseline treatment but was mailed in late November 2016, near the start of the open enrollment period. Based on operational considerations, approximately 21 percent of the treatment sample was assigned to the early mailing variant. The remainder of the treatment sample was randomly divided among the baseline treatment and the other two variants in equal proportions. Finally, the baseline treatment and each of the three variants were randomly divided into two even-size groups, one of which had a Spanish-language translation printed on the reverse side of the letter and one of which did not. Appendix Table A.1 summarizes

\footnotetext{
${ }^{14}$ Households were block-randomized based on age and gender of primary filer, marital status, number of dependents, income, the presence of self-employment income, 2014 penalty status, and whether the taxpayer's state expanded Medicaid and/or participated in the federal marketplace during 2017.
} 
the allocation of the sample across the various treatment groups.

\subsection{Summary Statistics and Balance Checks}

Table 1 contains individual-level summary statistics for the experimental sample and information about covariate balance. As benchmarks, Columns 1 and 2 provide summary statistics for a random 1\% sample of the overall population of tax returns (Column 1) as well as for the full population of returns that did not indicate full-year coverage for 2015 (Column 2). ${ }^{15}$ Relative to these baseline populations, individuals in our sample (Column 3) are younger, more likely to be male, and less likely to be married. Notably, although our sample is much lower income than the overall population, it is higher income on average than the population without full-year coverage, many of whom qualified for an income-based exemption from the penalty.

Although a household being included in our sample implies that at least one individual in the household lacked coverage for one or more months during the year, that individual may have had coverage for other months during the year, and other individuals in the household may have been enrolled in coverage during every month of the year. In particular, Table 1 shows that over half $(58 \%)$ of the individuals in our sample had coverage in at least one month in 2015, and a substantial minority (28\%) had coverage in every month of 2015. Along both of these measures, the fraction of our sample with coverage rose from 2015 to 2016. Finally, note that in both 2015 and 2016, most individuals had either full-year coverage or zero months of coverage.

Columns 4-6 of Table 1 investigate covariate balance between the treatment and control groups. Consistent with the randomized design and large sample sizes, the treatment and control groups are quite similar in most respects. ${ }^{16}$

\section{Coverage Effects}

This section investigates the effect of the treatment on individuals' subsequent coverage decisions. We first present results relating to coverage in the year following the intervention. Next, we turn to longer-term coverage outcomes. Finally, we explore the total

\footnotetext{
${ }^{15}$ The latter category contains taxpayers who claimed an exemption and taxpayers who incorrectly failed to report a penalty.

${ }^{16}$ The two characteristics in which differences between the treatment and control groups are statistically significant are whether the individual's household claimed a 2014 exemption (0.2 percentage point difference) and whether the individual was enrolled in full-year 2016 coverage ( 0.1 percentage point difference). In both of these cases, the magnitude of the difference is quite small, and our results are not sensitive to controlling for these or other observable characteristics. For both of these variables, it is also conceivable that the difference reflects an effect of the treatment, since receiving the letter may have prompted individuals to file an amended 2014 return to avoid the penalty, or may have corrected an error on the part of their insurer or employer that otherwise would have resulted in them appearing to lack 2016 coverage.
} 
additional coverage induced by the pilot among those whose coverage decisions were affected.

\subsection{First-Year Coverage Effects}

We first investigate how the treatment affected the likelihood of obtaining coverage in 2017, the first year following the intervention. Under our randomized design, this effect is identified by comparing the means of the coverage outcomes across the treatment and control groups. Because individuals listed on the same tax return were assigned to the same treatment group, we present standard errors clustered at the household-level.

Column 1 of Table 2 presents the results of this analysis for the full experimental sample. The treatment (i.e., receiving any letter) increased the probability of obtaining at least one month of 2017 coverage by 0.85 percentage points, a $1.2 \%$ increase relative to the control group mean of $69 \%$. Put differently, the treatment reduced the share of the sample without any 2017 coverage by $2.7 \%$. The treatment effect is precisely estimated; the $95 \%$ confidence interval ranges from 0.74 to 0.96 percentage points.

As indicated by the control group mean, approximately two-thirds of the overall sample would have enrolled in at least some coverage even absent the intervention. Although we cannot identify which individuals fall into this category, one proxy might be the number of months of 2016 coverage in which the individual enrolled. Columns 2 through 5 of Table 2 investigate the effect of the treatment on the probability of obtaining any 2017 coverage, broken out by months of 2016 coverage. Because the intervention may have affected coverage decisions for December 2016, we restrict our focus to the first 11 months of 2016. Among individuals who lacked any 2016 coverage, only $27 \%$ of the control group obtained any coverage in 2017. For this group, the treatment increased the probability of 2017 coverage by 1.8 percentage points, a $6.7 \%$ increase relative to the control. Columns 3-4 show that as months of 2016 coverage increase, the fraction of the sample that would obtain 2017 coverage increases as well and the magnitude of the treatment effect declines monotonically. ${ }^{17}$

Column 5 of Table 2 investigates the treatment effect for individuals with full-year coverage in 2016 - a group constituting $42 \%$ of our sample. The control group mean $(97 \%)$ indicates that the vast majority of individuals in this group are likely to obtain at least some 2017 coverage as well, even absent the intervention. Hence, there is little scope for the intervention to increase the probability of obtaining 2017 coverage. Consistent with this fact pattern, the estimated treatment effect among individuals with full-year coverage in 2016 is only slightly positive (0.08 percentage points). In Column 6, and in subsequent specifications, we exclude this group from our analysis. Among individuals

\footnotetext{
${ }^{17}$ Appendix Table A.2 investigates the role of 2015 coverage in predicting how the treatment affects an individual's 2017 coverage decision. The results suggest that individuals who lacked 2015 coverage are more likely to respond to the intervention, but that 2016 coverage plays a more important role.
} 
who lacked coverage in at least one month during 2016, the treatment increased the probability of 2017 coverage by 1.3 percentage points, a $2.8 \%$ increase relative to the control.

We next investigate the form of coverage induced by the intervention. As described in Section 2, the individual penalty can be avoided by enrolling in one of various forms of coverage. Table 3 analyzes the effect of the treatment on the likelihood of obtaining one or more months of 2017 coverage, by type of coverage. The largest effect is on Exchange coverage: the treatment increases the probability of having any 2017 coverage by 1.02 percentage points, a 30\% increase relative to the control group mean. The effect on Medicaid coverage is just under half as large in absolute terms, 0.45 percentage points, but constitutes only a $2.4 \%$ increase relative to the control group mean. We observe a small and statistically insignificant increase in employer-sponsored coverage, which is not surprising given the letters were received too late to participate in most employers' open enrollment windows. We also observe near-zero effects on off-exchange individual coverage as well as coverage provided by the Veterans Administration. Finally, as a placebo check, we confirm that we observe no effect on the likelihood of Medicare coverage during the year. ${ }^{18}$

We next explore treatment effect heterogeneity based on age and income. Table 4 estimates the treatment effect separately by age category. Recall that our sample population over-represents younger individuals, since older adults were less likely to pay the penalty for lacking coverage. Interestingly, up through age 64, the probability of having 2017 coverage in the control group declines monotonically with age, whereas the treatment effect mostly increases. Taken together, these results suggests that although older adults are more likely to obtain coverage, those who do not are particularly unlikely to do so absent the treatment, but also particularly responsive to the treatment. This pattern could emerge if some of those who lack coverage in the years prior to reaching Medicare eligibility are intentionally deferring their consumption of health services (Card, Dobkin and Maestas, 2008; Freed, 2017), but, absent the treatment, are also over-estimating the net financial cost of coverage. Column 5 of Table 4 shows that the intervention appears to increase coverage for individuals aged 65 or older, although the smaller fraction of the sample in this age range means that the estimates are less precise than for other age groups.

Table 5 considers heterogeneity in the treatment effect by household income. The measure of household income we rely on is the ratio of the household's modified adjusted gross income in 2016 relative to the applicable federal poverty line (FPL). The treatment effect peaks among households in the 100\%-138\% FPL region, whose incomes are likely

\footnotetext{
${ }^{18}$ Note that summing the treatment effect across Columns 1-6 of Table 3 yields a larger effect (1.59 percentage points) than the total coverage effect (Column 6 of Table 2), suggesting that some individuals were induced to enroll in multiple forms of coverage during the year.
} 
to qualify them for Medicaid in the states that adopted the ACA's Medicaid eligibility expansion, and declines monotonically in both directions. ${ }^{19}$ Appendix Tables A.3 and A.4 further investigate the effects by income on Medicaid and Exchange coverage, and by whether the individual's state expanded Medicaid eligibility. In expansion states, the intervention significantly increased the likelihood of obtaining Medicaid coverage, especially for individuals in the $100-138 \%$ FPL income range. Effects on Medicaid coverage were much smaller or non-existent in non-expansion states. In contrast, positive effects on Exchange coverage were present in both expansion and non-expansion states, although the effects were larger in the latter than in the former for low-income households.

\subsection{Timing of Coverage Effects}

In this subsection we focus on the timing and duration of the intervention's effect on coverage. Figure 1a plots the raw coverage rates for the treatment and control groups by month, and Figure 1b plots the monthly difference in coverage rates. Consistent with the randomized design, the difference in coverage rates is approximately zero during 2016. Both treatment and control individuals enroll in coverage at a higher rate in January 2017, but the increase for the treatment group is larger than for the control. The difference in coverage rates between the treatment and control continues to grow in February 2017, and peaks at 1.51 percentage points in March 2017. Given the timing of the letter and the rules for beginning coverage described in Section 2, this pattern is consistent with most individuals signing up for coverage just before the open enrollment deadline and having March as their first effective month of Exchange coverage. Following March, we observe a gradual decline in the treatment effect over the course of the year. ${ }^{20}$ Even in December 2017, however, the difference in coverage between the treatment and control groups is 1.06 percentage points and remains statistically significant.

Enrollment rates for both the treatment group and control increase between December 2017 and January 2018, but the magnitude of the increase is smaller for the treatment than the control. This may be because there was greater scope for increased 2018 coverage for the control group or it may be that some of those induced by the intervention to enroll in 2017 failed to re-enroll in 2018. Nonetheless, the difference in coverage rates between

\footnotetext{
${ }^{19}$ In states that expanded Medicaid, most individuals with household income below $138 \%$ of the FPL qualify for Medicaid. In all states, individuals who qualify for Medicaid are not eligible for the premium tax credit that subsidizes Exchange coverage.

${ }^{20}$ Attrition appears to be driven by individuals who enrolled in Exchange coverage; we observe a more gradual decline over the course of 2017 in the effect of the treatment on Medicaid coverage (see Appendix Figure A.2). Interestingly, the drop-off in Exchange coverage appears steepest in the first few months following enrollment, in contrast to a pattern others have identified in which individuals tend to drop coverage at the end of the year, potentially to take advantage of the short-term gap exemption (Diamond et al., 2018). The difference may be due to less strategic behavior among the individuals in our sample, as suggested by the fact that inclusion into our sample is based on having failed to avoid the penalty in a prior year.
} 
the treatment and control groups remains positive and statistically significant throughout 2018, and declines only slightly over the course of the year. ${ }^{21}$ Appendix Table A.5 shows that the types of coverage increased by the intervention in 2018 was similar to the types increased during the prior year. We thus conclude that much - but not all - of the effect of the intervention on coverage persists for the two years following treatment.

\subsection{Intensive Margin Coverage Effects}

Thus far our focus has been on the extensive margin of coverage decisions - i.e., the probability of obtaining positive months of coverage in the year or two years following treatment. In this subsection we consider how the treatment affected the number of months of coverage in which individuals enrolled. We also investigate the share of individuals who increased their months of coverage because of the treatment and the average coverage increase among this group. We explore these questions in some depth because answering them provides important context for interpreting the mortality effects we estimate in Section 5.

Let $Z_{i}$ indicate whether individual $i$ is in the treatment group and let $C_{i}(0)$ and $C_{i}(1)$ denote the months of coverage that $i$ would obtain if assigned to the control and treatment group, respectively. Thus, $i$ 's observed coverage, $C_{i}$, is given by $C_{i}=C_{i}(0)+$ $Z_{i}\left(C_{i}(1)-C_{i}(0)\right)$. Random assignment guarantees the independence of treatment and the potential coverage outcomes, $Z_{i} \perp\left(C_{i}(0), C_{i}(1)\right)$. Hence, the population average effect of the intervention on coverage is equal to the difference in mean coverage between treatment and control, $E\left[C_{i}(1)-C_{i}(0)\right]=E\left[C_{i} \mid Z_{i}=1\right]-E\left[C_{i} \mid Z_{i}=0\right]$.

Column 1 of Table 6 reports the sample mean difference in months of 2017 coverage between the treatment and control. On average, the treatment increases coverage by 0.14 months in 2017. Note that this effect potentially captures changes in behavior on both the extensive and intensive margins (i.e., any coverage and number of coverage months, respectively). At a combined printing and postage cost of approximately $\$ 0.49$ per letter, this estimated effect implies an average outreach cost of less than $\$ 43.05$ per year of new coverage. $^{22}$

To shed more light on the change in coverage induced by the treatment, Figure 2 plots

\footnotetext{
${ }^{21}$ To the extent that the additional 2017 coverage induced by the treatment prevents 2017 mortality (as we explore in section 5), it could mechanically increase the observed treatment effect on 2018 coverage by increasing the share of the treatment group that is alive to purchase coverage in that year. Because the magnitude of the mortality effect we observe is so much smaller than the coverage effect, however, this mechanism is unlikely to play an important role in explaining the coverage results.

${ }^{22}$ This cost estimate overstates the number of letters sent per additional year of coverage induced because it does not account for the fact that only one letter was sent to each married couple filing jointly. Including individuals with full-year 2016 coverage yields a treatment effect of 0.094 months for 2017 coverage, which translates into an average cost of $\$ 62.90$ per year of new coverage among the overall pilot population. Note that these estimates do not account for the cost of IRS, Treasury, or HHS staff time associated with the implementation or initial development of the intervention, or the budgetary cost of premium or cost-sharing subsidies.
} 
the difference in probability mass functions of 2017 coverage months between treatment and control. Treatment group members are less likely to have 0 months of 2017 coverage, and more likely to have 10, 11, or 12 months of 2017 coverage. One possibility consistent with this pattern is that the treatment primarily caused individuals who would have enrolled in 0 months of coverage (absent the treatment) to instead enroll in 10-12 months of coverage. Alternatively, the Figure is also consistent with the treatment increasing coverage (by a smaller number of months) among individuals who would have enrolled in some non-zero amount of coverage even absent the treatment.

Without additional assumptions, we cannot identify the share of individuals who changed their behavior because of the treatment or the average coverage increase among this group. To derive bounds on these parameters, we assume the effect of the treatment is weakly monotonic, ${ }^{23} C_{i}(1) \geq C_{i}(0)$, which allows us to write:

$$
E\left[C_{i}(1)-C_{i}(0)\right]=\operatorname{Pr}\left(C_{i}(1)>C_{i}(0)\right) E\left[C_{i}(1)-C_{i}(0) \mid C_{i}(1)>C_{i}(0)\right]
$$

To estimate a sharp lower bound on the share of individuals who respond to the treatment ("the responders"), $\operatorname{Pr}\left(C_{i}(1)>C_{i}(0)\right)$, we follow Borusyak (2015) and compute the total variation distance between the treatment and control coverage distributions for 2017:

$$
d_{T V}=1-\sum_{m=0}^{12} \min \left\{f^{0}(m), f^{1}(m)\right\}
$$

where $f^{j}(m)$ denotes the probability mass function of coverage month $m$ for the treatment group corresponding to $Z=j$. Column 2 of Table 6 estimates $d_{T V}$ in our setting; we find that at least $1.4 \%$ of our sample population enrolled in additional coverage because of the pilot. Substituting this result into (1) and using the estimated mean treatment effect from Column 1 yields an upper bound for the coverage increase among those who respond of 10.0 months. $^{24}$

To estimate an upper bound on the share of responders, we take advantage of the discrete nature of the coverage decision. From (1), $\operatorname{Pr}\left(C_{i}(1)>C_{i}(0)\right)$ is maximized when $E\left[C_{i}(1)-C_{i}(0) \mid C_{i}(1)>C_{i}(0)\right]$ is minimized. Because the minimum increment by which coverage can be adjusted is one month, it follows that $E\left[C_{i}(1)-C_{i}(0) \mid C_{i}(1)>C_{i}(0)\right] \geq$ 1, and therefore that $\operatorname{Pr}\left(C_{i}(1)>C_{i}(0)\right) \leq E\left[C_{i}(1)-C_{i}(0)\right]$. Inspection of the coverage distribution confirms this possibility is feasible (see Appendix Table A.6) and therefore that the bound is sharp. The results of this exercise are summarized in Column 3 of Table 6. Summarizing the results of this analysis, the intervention caused between $1.4 \%$ and $14.0 \%$ of the sample to increase their coverage during 2017. Columns 4-6 repeat this exercise for total coverage during 2017 and 2018.

\footnotetext{
${ }^{23}$ We discuss this assumption in greater detail in Section 5.2.

${ }^{24}$ Appendix Table A.6 presents the aggregated data underlying these calculations.
} 


\section{$5 \quad$ Mortality Effects}

In this section, we exploit the exogenous variation in health insurance induced by the pilot to estimate the effect of the newly added coverage on mortality. To increase statistical power, we restrict most of the analyses in this section to previously uninsured individuals between the ages of 45-64 - a group for whom death is less rare compared to younger individuals and a group for whom the effect of our intervention on coverage is relatively large (see Table 4). ${ }^{25}$ We consider the robustness of our results to other sample populations below.

\subsection{The Effect of the Outreach Intervention on Mortality}

Panel A of Figure 3 presents the cumulative mortality rate over time for our sample, broken out by treatment group assignment, and Panel B plots the difference between the treatment groups in cumulative mortality over time. The mortality rates for the two groups appear similar during 2016 but diverge over the 2 years following the pilot intervention. The figure thus provides preliminary evidence that the intervention reduced mortality in the treatment group relative to the control. ${ }^{26}$

Table 7 presents regression estimates for the effect of the intervention on 2-year mortality (i.e., deaths that occurred in 2017 or 2018). The overall mortality rate for the control group during this period was approximately 1\%. Given the randomized design, the difference in the mortality rate between the treatment and control groups (i.e., the intent-to-treat) captures the causal effect of the intervention on mortality. We estimate that the intervention reduced mortality by 6.3 basis points during the 2-year sample period (Column 1). The p-value associated with this estimate is approximately $p=0.01$; a permutation test yields similar results (Appendix Figure A.5). The estimated effect is similar, but slightly smaller in magnitude (6.1 basis points), when individual- and household-level controls are included in the regression (Column 2). Focusing on this more conservative result, we estimate that one fewer death occurred during our sample period for every 1,648 individuals in this population that were sent a letter. Note that

\footnotetext{
${ }^{25}$ Studies of health insurance on mortality typically restrict the sample population to older adults, but the specific age range varies by study (compare Baker et al., 2006; Sommers, Baicker and Epstein, 2012; Khatana et al., 2019; Miller et al., 2019). In our setting, the age range we consider shapes the power of our analysis by affecting the strength of the first stage (increasing in the minimum age included), the baseline mortality rate (increasing in the minimum age included), and the sample size (decreasing in the minimum age included). To consider these factors together, we simulate the effect of the pilot on mortality under a range of assumptions about the magnitude of the effect and the baseline mortality of the compliers. For 8 of the 12 combinations of parameter values we consider, the 45-64 year-old age range maximizes the likelihood of detecting an effect of the treatment on mortality. See Appendix Figure A.3 for details. As in our coverage analyses, we focus on individuals who lacked coverage at some point during the prior year because the effects of the pilot on coverage appear to be limited to this group (see Table (2)).

${ }^{26}$ The same pattern is also present (but noisier) in Appendix Figure A.4, which plots new deaths (rather than cumulative mortality) over time by treatment and control group assignment.
} 
this result speaks to the average number of life-years saved during the sample period but not to their distribution; that is, we cannot separately identify how many lives were extended from the average length of extension. ${ }^{27}$

To interpret our results, we adopt the assumption that the intervention did not affect mortality through a channel other than inducing taxpayers to enroll in additional coverage. This exclusion restriction might be violated, for example, if receiving a letter from the IRS directly contributes to mortality by causing health- or financial-related stress on the part of recipients. Of course, we cannot entirely rule out such possibilities, but it is difficult to conceive of plausible mechanisms by which the assumption would be violated in our setting. ${ }^{28}$ Indeed, because our intervention does not provide individuals with newly available coverage, it avoids a potential concern that is present in lottery-based evaluations, i.e., that the effect of coverage on health outcomes is conflated with the psychological effect of "winning" a lottery to obtain coverage (a possibility discussed in Finkelstein et al., 2012). Under the exclusion restriction, our results provides evidence that the coverage induced by the intervention reduced taxpayers' mortality.

We conduct two placebo checks to assess the assumptions underlying our interpretation of the mortality results. First, to investigate the possibility that the observed mortality difference in treatment and control resulted from preexisting health differences or changes in reporting behavior, Column 3 of Table 7 presents the effects of the treatment on 2016 mortality (before the intervention occurred); the estimated effect is near-zero and not statistically significant. The second placebo focuses on the exclusion restriction -i.e., the assumption that the intervention affected mortality only through the change in coverage it induced. To test this assumption, Column 4 of Table 7 presents the effect of the treatment on mortality for a subset of the population for which the intervention was significantly less likely to induce new coverage: individuals who were enrolled in full-year coverage during 2016. If the intervention affected mortality through a channel other than inducing new coverage, we might observe its effect here as well. Instead, we estimate the effect of the intervention on mortality for this group to be much smaller ( 1 basis point) and not statistically significant.

We consider several other robustness checks as well. Appendix Table A.7 shows that the presence (but not the magnitude) of the mortality effect is reasonably robust to adopt-

\footnotetext{
${ }^{27}$ For example, the following two cases would contribute equally to our observed effect: (1) the intervention causes one person to die on $1 / 1 / 2019$ instead of $1 / 1 / 2017$; and, (2) the intervention causes one person to die on $1 / 1 / 2018$ instead of $1 / 1 / 2017$ and a different person to die on $1 / 1 / 2019$ instead of $1 / 1 / 2018$.

${ }^{28}$ One possibility is that some of the individuals induced to apply for coverage are subsequently recruited to participate in safety net programs like SNAP or TANF, and it is participation in these programs, rather than health insurance, that reduces mortality. However, our finding that the mortality effects are primarily concentrated among individuals in households above the Medicaid income threshold (discussed below) provides evidence against this hypothesis. Our results are consistent with the possibility that mortality is reduced via financial rather than medical effects of coverage, but the medical mechanism strikes us as more plausible, especially over the relatively short time period we observe.
} 
ing alternative age cutoffs for defining the sample. Appendix Table A.8 includes in the analysis individuals who were already fully insured in the year prior to the intervention, and who therefore lacked a substantial first-stage effect. As expected, the estimated effect of the intervention is attenuated for this sample (4.5 basis points), but remains statistically significant. Finally, Appendix Table A.9 shows that the presence of a mortality effect is not sensitive to estimating a non-linear limited dependent variable or duration model; for example, a log-rank test rejects the null hypothesis of equality between the treatment and control group survival curves.

To further investigate variation in the observed mortality effect by age, Figure 4 plots the estimated effect of the intervention by 10-year age bin. The figure provides evidence that the coverage induced by the pilot reduced mortality even among the younger group of middle-aged adults we consider ( $45-54$ year-olds). The estimated mortality reduction for 55-64 year-olds is of similar magnitude but is less precisely estimated. In contrast, we observe no reductions in mortality among age groups younger than 45, consistent with the prior quasi-experimental findings reported in Sommers, Baicker and Epstein (2012) and Miller et al. (2019).

Appendix Table A.10 presents several additional analyses to better understand the primary mortality results. Columns 1 and 2 estimate the effect of the intervention on mortality separately for men and women; the estimated effect for women is somewhat larger in both absolute magnitude and percentage terms, but the difference is not statistically significant. We next investigate whether the observed mortality effect is driven by Medicaid or Exchange enrollment. To do so, we exploit the fact that most of the observed increase in Medicaid enrollment comes from individuals whose 2016 household income is below the Medicaid threshold (see Table A.3). Columns 3 and 4 show that the estimated mortality reduction is larger for those whose incomes exceed the Medicaid threshold, consistent with the observed reduction in mortality being primarily driven by enrollment in Exchange coverage.

Turning to the mechanism by which coverage reduces mortality, a limitation of our analysis is that we lack data on cause of death. However, the fact that we observe a mortality effect within the initial 1-2 years after the intervention narrows the range of possibilities. For coverage to reduce mortality over this time horizon, it must affect conditions that: (1) can cause death quickly if left untreated or unmanaged, and (2) for which treatment or management can prevent or delay mortality. For example, individuals lacking health insurance may delay seeking care when experiencing symptoms of acute conditions (e.g., heart attack or stroke), and such delays increase the likelihood of short-term mortality (Smolderen et al., 2010; Medford-Davis et al., 2016). Consistent with this hypothesis, recall that our observed mortality effect is concentrated among individuals with incomes too high to qualify for Medicaid (including retroactive coverage), and who may therefore expect a larger bill from an emergency room visit. In addition, 
prior research suggests women are more likely to delay obtaining emergency care than men (Safdar, Lichtman and D'Onofrio, 2012), which may explain why we observe comparable mortality effects for women and men despite the latter's higher baseline mortality risk. Separately, obtaining coverage may reduce mortality by causing the diagnosis of certain chronic conditions for which treatment has rapid protective effects. For example, cardiovascular drugs have been observed to reduce mortality from heart disease within months of beginning treatment (Aronow et al., 2001; Cannon et al., 2004), and Khatana et al. (2019) report reductions in mortality from cardiovascular disease in the initial years following state Medicaid expansions. In contrast, coverage would not be expected to drive such rapid mortality effects by inducing diagnosis of chronic conditions that are susceptible to early- but not late-stage treatment, such as certain forms of cancer (Sommers, Long and Baicker, 2014).

\subsection{The Effect of Outreach-Induced Coverage on Mortality}

The results in the prior sub-section provide evidence that the coverage induced by the intervention reduced mortality, but do not directly speak to the magnitude of this effect. In this sub-section, we exploit treatment group assignment as an instrument for coverage to better understand the relationship between coverage and mortality.

\subsubsection{Empirical Framework}

As above, let $Z_{i}$ indicate whether individual $i$ was assigned to the treatment group. $C_{i}$ denotes the months of coverage in which $i$ was enrolled during 2017 and 2018, and $C_{i}(Z)$ denotes the months of coverage over the same time period in which $i$ would have enrolled had $i$ been assigned to treatment group $Z$. Let $Y_{i}$ indicate whether $i$ died in either 2017 or 2018 and $Y_{i}(C)$ indicate whether $i$ would have died during this period had $i$ enrolled in $C$ months of coverage. Note that because treatment group status was randomly assigned, the potential outcomes $Y_{i}(C)$ and $C_{i}(Z)$ are jointly independent of $Z_{i}$, for each value of $C$ and $Z$.

We assume that the effect of the intervention on coverage is monotonic: each individual obtains (weakly) more coverage when assigned to the treatment group rather than the control, $C_{i}(1) \geq C_{i}(0) \forall i$. Because we observe coverage decisions under either the treatment or the control (but not both), monotonicity is not directly verifiable. However, a necessary condition for monotonicity to hold in our setting is that the CDFs of coverage for the treatment and control groups do not cross one another, $\operatorname{Pr}\left(C_{i}(1) \leq m\right) \leq \operatorname{Pr}\left(C_{i}(0) \leq m\right) \forall m \in\{0,1, \ldots, 24\}$ (Angrist and Imbens, 1995). Appendix Figure A.6 establishes that this condition is satisfied in our data. In addition, because monotonicity must hold for each individual, the assumption also implies that the cumulative distributions should not cross among any subset of the sample (at least 
in expectation). Appendix Figure A.7 presents evidence consistent with this hypothesis from various demographic subgroups.

When monotonicity, independence, and the exclusion restriction (described above) are satisfied, the two-stage least squares estimator identifies the average causal response (ACR) of a treatment - i.e., the treatment's per-unit effect, averaged over the additional units of treatment that are due to the instrument (Angrist and Imbens, 1995):

$$
\frac{E\left[Y_{i} \mid Z_{i}=1\right]-E\left[Y_{i} \mid Z_{i}=0\right]}{E\left[C_{i} \mid Z_{i}=1\right]-E\left[C_{i} \mid Z_{i}=0\right]}=\sum_{m=1}^{12} w_{m} E\left[Y_{i}(m)-Y_{i}(m-1) \mid C_{i}(1) \geq m>C_{i}(0)\right]
$$

where

$$
w_{m}=\frac{\operatorname{Pr}\left(C_{i}(1) \geq m>C_{i}(0)\right)}{\sum_{j=1}^{24} \operatorname{Pr}\left(C_{i}(1) \geq j>C_{i}(0)\right)}
$$

In our setting, the ACR corresponds to the per-month effect of coverage on mortality, averaged over the additional months of coverage that individuals enrolled in because of the pilot.

\subsubsection{Instrumental Variable Results}

Table 8 presents results for the instrumental variables analysis. As a benchmark, Column 1 presents the results from an OLS regression of mortality on coverage. Each additional month of coverage is associated with a small (2.6 basis points) but statistically significant reduction in the probability of dying. However, the OLS estimates may conflate differences in mortality with differences in the health of those who select into coverage.

Column 2 of Table 8 presents the first stage effect of the intervention on months of coverage. ${ }^{29}$ Among the 45-64 year-old population used in the mortality analysis, the average effect of the intervention on coverage is an increase of 0.36 months. Scaling the estimated reduced form effect of the intervention (Column 1 of Table 7 ) by the first stage coefficient yields our two-stage least squares estimate of -0.18 percentage points (Column 3 ). Under the independence, monotonicity, and the exclusion restriction assumptions described above, this coefficient estimates the average causal response of coverage on mortality - i.e., the average per-month effect of the extra coverage-months induced by the intervention. ${ }^{30}$ The $95 \%$ confidence interval extends from -0.31 to -0.04 percentage points. It is striking

\footnotetext{
${ }^{29}$ We focus on months of coverage enrolled in during the sample period rather than a binary indicator for having any coverage; using the latter would violate the exclusion restriction if some individuals, who would have enrolled in positive months of coverage even absent the intervention, enroll in more months of coverage because of the intervention and these additional coverage-months contribute to the observed mortality effect.

${ }^{30}$ Below, we present suggestive evidence that enrolling in an additional year of coverage reduces mortality by less than 12 times this per-month effect.
} 
to note that the OLS and 2SLS confidence intervals do not overlap, consistent with the possibility that adverse selection into coverage attenuates cross-sectional estimates of the effect of coverage on mortality.

To increase the precision of the IV analysis, we experimented with two additional specifications. Column 4 replicates the two-stage least-squares specification but additionally includes demographic and geographic controls. The results are similar to the specification without controls. Column 5 expands the sample to include the full population of 45-64 year-olds, including those who were fully insured in the year prior to the intervention. Because this group had a much smaller first-stage than the overall population, to increase power we include an interaction between the treatment and an indicator for having coverage in each month of 2016 . The resulting point estimate is nearly identical to that obtained from our main IV specification.

Interpreting the average causal response (ACR) of coverage on mortality requires understanding which taxpayers enrolled in additional coverage because of the intervention, as well as the nature of the additional coverage-months enrolled in by this group. The remainder of this section provides suggestive evidence on these issues.

First, to shed light on the distribution of new coverage-months induced by the treatment, we estimate, for each $m$ :

$$
C_{i}^{m}=\alpha+\beta_{m} Z_{i}+\varepsilon
$$

where $C_{i}^{m}$ indicates whether $i$ attains at least $m$ months of coverage, $C_{i} \geq m$. The $\beta_{m}$ coefficients identify the weights $\left(w_{m}\right)$ from Equation $(2)$ that aggregate the per-month effects of coverage into the ACR. ${ }^{31}$ Appendix Figure A.8 displays the results of this analysis. The intervention added more initial coverage-months than subsequent coverage-months; for example, 15.2 percent of the coverage-months added by the intervention constituted the first, second, or third month of coverage in which the individual was enrolled during 2017-18, as compared to 6.7 percent of coverage-months that constituted the $22 \mathrm{nd}, 23 \mathrm{rd}$, or 24th month of coverage for the individual during the same time period. This suggests the ACR is disproportionately weighted towards the per-month effect of coverage of initial coverage-months. An important implication is that if the relationship between coverage and mortality is concave, simply multiplying the ACR by 12 would over-estimate the effect of annual coverage on mortality. Such concavity might arise, for example, if individuals can obtain many of the health benefits of full-year coverage by fitting their health service consumption into the months in which they do have coverage (Diamond et al., 2018). Similarly, for individuals who previously lacked coverage, purchasing even a few months of coverage may be enough to induce individuals to visit a doctor, and

\footnotetext{
${ }^{31}$ In particular, under independence and monotonicity, $\beta_{m}$ identifies $\operatorname{Pr}\left(C_{i}(1) \geq m>C_{i}(0)\right)$, which implies $w_{m}=\frac{\beta_{m}}{\Sigma_{m} \beta_{m}}$.
} 
some fraction of those that do so obtain treatment for a life-threatening, but previously undiagnosed, condition.

A second, and related, point is that the ACR may exceed the steady-state effects of coverage on mortality to the extent it is identified from new coverage-months enrolled in by the recently uninsured. Without insurance, individuals may avoid or delay beneficial health services, especially when they expect to qualify for Medicare coverage in a few years' time (Card, Dobkin and Maestas, 2008; Alpert, Lakdawalla and Sood, 2016; Freed, 2017). Because the health benefits of the services consumed by the newly insured will be higher than the long-term insured, the first year of coverage may have a larger effect on health than subsequent years of coverage. ${ }^{32}$ To shed light on this hypothesis, Table 9 describes characteristics of individuals who enroll in any 2017 coverage because of the treatment ("the compliers"). ${ }^{33}$ We find strong evidence that compliers are in fact less likely to be insured in prior years than the others in our sample. Hence, the coveragemonths that identify the ACR disproportionately constitute coverage for the recently uninsured.

Third, as a benchmark for interpreting the magnitude of the estimated effect, recall that the average mortality rate among the control group over our two-year outcome period is approximately $1.0 \%$. However, the baseline mortality rate (i.e., the mortality rate without any insurance) for those who are induced to increase coverage by the treatment may exceed the average mortality rate among the overall control group, potentially by a significant margin (Miller et al., 2019). Identifying the baseline mortality rate among those who increased coverage because of the intervention requires additional structure in IV settings like ours in which the endogenous variable is non-binary. In an Appendix, we show that a sufficient condition to identify this parameter is that everyone who responds to the intervention does so exclusively along the extensive margin - i.e., $\operatorname{Pr}\left(C_{i}(1)>C_{i}(0)>0\right)=0$. This assumption strikes us as plausible when $C_{i}$ is defined in terms of 2017 coverage, given the timing of the intervention and the annual nature of the enrollment window, but not for 2017-18 coverage, since the intervention likely caused some individuals to enroll in 2017 coverage who would have enrolled in 2018 coverage

\footnotetext{
${ }^{32}$ Although the ACR may over-state the steady-state effect of coverage, it may simultaneously understate the longer-term mortality benefits. For example, if obtaining 2017 coverage extends one's life from 2019 to 2020, that effect will not be reflected in the ACR. With only two years of outcome data, our analysis is not well-suited to study these longer-term effects or to disentangle the contemporaneous versus long-term effects of coverage.

${ }^{33}$ In settings with a binary instrument and binary endogenous variable, it is common to report characteristics of the compliers (Abadie, 2002). In our setting, because coverage is non-binary, the group we label as the compliers corresponds to a subset of all those who respond to the instrument - specifically, those for whom the instrument affects the number of months of 2017 coverage in which they enroll. This analysis therefore omits individuals who respond with respect to two other margins: (1) those for whom the instrument affects their 2018 - but not 2017 - coverage (e.g., because they miss the 2017 open enrollment deadline), and (2) those who increase their 2017 coverage in response to the instrument but only on the intensive margin. The results are similar when we define compliers in related ways, such as those who enroll in any 2017 or 2018 coverage because of the instrument.
} 
absent treatment. ${ }^{34}$ Imposing this assumption that the 2017 coverage response occurred exclusively along the extensive margin, we estimate a baseline one-year mortality rate among the compliers of $0.7 \%$ (Table 9 ). Multiplying this estimated rate by two yields an estimated baseline mortality rate among compliers of $1.4 \%$ during our two-year sample period, approximately $40 \%$ higher than the overall control group mean. Hence, our point estimate implies that each month of coverage induced by the intervention reduced mortality by approximately $11.9 \%$ during our sample period. Note that the magnitude of this estimate constitutes additional evidence against a linear dose-response relationship between coverage and mortality; if the relationship was linear, 12 months of coverage would translate into an over $100 \%$ decline in mortality during the sample period, which is of course larger than what is possible. However, as discussed above, this point estimate is consistent with a range of effect sizes; the upper bound of our confidence interval implies that each month of coverage (on average) reduces baseline mortality among those who enroll in coverage by approximately $2.4 \%$, which is consistent with a linear relationship between coverage and mortality.

Finally, there are at least two possible reasons why our estimated ACR may be biased upward in magnitude. The first concerns a failure of the monotonicity assumption. If some individuals are "nudge averse," receiving the IRS letter could cause them to enroll in less coverage than they would otherwise obtain (Gill, 2018). If the protective effect of coverage on mortality is lower than average for this group, our first-stage would underestimate the true effect of the intervention on coverage and bias the 2SLS estimate away from zero. The second possibility is that the health benefits of coverage are not limited to the individuals who enroll, but also spill over to others in the same household or community. ${ }^{35}$ If so, this would also bias the 2SLS estimate upwards in magnitude. Although we cannot rule out these possibilities, we note that neither would predict our observing an effect of the intervention on mortality (i.e., a non-zero intent-to-treat) if none was present.

\subsection{Comparison to Findings from Other Research}

With respect to our mortality analysis, the previous study closest to ours in design is the Oregon Health Insurance Study (Finkelstein et al., 2012), which randomized access to Medicaid among a low-income population of applicants. The Oregon study did not find a statistically significant effect of coverage on mortality; however, our $95 \%$ confidence interval substantially overlaps with theirs, with both including average causal responses of

\footnotetext{
${ }^{34}$ Appendix Figure A.9 provides additional evidence that is consistent with the assumption holding for 2017 coverage: $\operatorname{Pr}\left(C_{i}(1)=0\right)<\operatorname{Pr}\left(C_{i}(0)=0\right)$ and for each $m \in\{1,2, \ldots 12\}$, either $\operatorname{Pr}\left(C_{i}(1)=m\right)>$ $\operatorname{Pr}\left(C_{i}(0)=m\right)$ or else the difference is not statistically significant.

${ }^{35} \mathrm{On}$ this point, we refer readers to the discussion and literature review in Borgschulte and Vogler (2019), who argue that such spillover effects may explain why studies in this literature tend to observe very large effects of coverage among the treated.
} 
coverage on mortality between -0.032 and -0.101 percentage points (see Appendix Table A.11, Column 1). ${ }^{36}$ In addition, the average age in the Oregon study population was 41, compared to 53 among the middle-aged adults included in our mortality analysis. If the protective effect of coverage on mortality increases (in absolute terms) in age, as suggested by Figure 4, it may be that differences in the age distribution of the two study populations contributes to the difference in point estimates. ${ }^{37}$ Indeed, re-weighting the Oregon analysis to reflect the age distribution of our middle-age sample increases the point estimate for the effect of coverage on mortality by almost $60 \%$ and increases the range of overlap in the estimated confidence intervals (Appendix Table A.11, Column 2). ${ }^{38}$

Turning to the non-experimental literature, our ability to compare our estimates to the results from the quasi-experimental studies referenced above is limited because most of these studies report mortality and coverage effects only over a 4- or 5-year time horizon. If the relationship between coverage and mortality is concave (as discussed in the prior subsection), the average per-month effect of coverage estimated in such studies is not comparable to ours. Luckily, although Miller et al. (2019) primarily focus on 4-year mortality in their study of the effect of the ACA Medicaid expansions, they also report estimates for the mortality and coverage effects in the first two years following the expansion. ${ }^{39}$ These estimates imply an ACR of coverage on 2-year mortality that is similar to the one we estimate (Appendix Table A.11, Column 3).

Finally, although our results are qualitatively consistent with much of the prior evidence that health insurance coverage reduces adult mortality, an important difference from the prior literature is the type of variation in coverage that we study. Whereas most prior literature studies expanded access to free coverage among those previously ineligi-

\footnotetext{
${ }^{36}$ In this section we focus on the confidence interval derived from our 2SLS specification with controls (Column 4 of Table 8).

${ }^{37}$ Consistent with this hypothesis, Miller et al. (2019) point out that the estimated mortality effect from the Oregon Study for older individuals is substantially larger in magnitude than for its overall sample population. A different possibility is that the discrepancy between our results and those obtained in the Oregon Study are driven by differences in the effectiveness of preventing mortality between Medicaid and Exchange coverage. Whereas the entire coverage effect studied by Finkelstein et al. was due to increased Medicaid coverage, our first stage is due to increased enrollment in both Medicaid and Exchange coverage. If only Exchange coverage reduces mortality, that fact might explain why we observe a mortality effect whereas they do not. However, this hypothesis is not consistent with findings from Sommers, Baicker and Epstein (2012) and Miller et al. (2019) that expanded Medicaid access did reduce mortality.

${ }^{38}$ The SSDI Accelerated Benefits demonstration project (Michalopoulos et al., 2011; Weathers and Stegman, 2012) - the only other randomized study of health insurance access on mortality of which we are aware - also failed to detect a beneficial effect of coverage on mortality. Like the Oregon study, its population, which was limited to 18-54 year-olds, was substantially younger than our mortality analysis sample. In addition, Weathers and Stegman (2012) report that the estimated effect of coverage on mortality for the study population may have been confounded by baseline differences in the prevalence of early-stage cancers among treatment and control group members.

${ }^{39}$ Even focusing on a 2-year outcome period, the ACR derived from the Miller et al. estimates is not directly comparable to ours because that study measures uninsurance at a single point in time each year rather than on a monthly basis (see the discussion in Section 5.2.2, above). In addition, Miller et al. focus exclusively on Medicaid coverage whereas we focus on having any form of insurance.
} 
ble for it, our intervention did not alter the coverage our sample population could access. Rather, it induced more individuals to enroll in coverage that was already available to them. In a standard adverse selection model, one might expect that individuals who elect not to enroll in available coverage are unlikely to benefit from such coverage - otherwise, they would have chosen to sign up. In contrast, our finding that the intervention reduced mortality for this group suggests that the behavioral frictions that reduce coverage takeup may be particularly concentrated among those individuals who would benefit from enrolling.

\section{Conclusion}

Drawing on a randomized pilot intervention, we examined the effect of outreach about tax incentives to enroll in health insurance coverage among taxpayers who had previously paid a penalty for lacking coverage. We found positive effects of the intervention on subsequent coverage enrollment decisions, particularly for taxpayers who were uninsured in the year prior to the intervention. We also found that the intervention reduced mortality among middle-aged adults in the subsequent two years, which we attribute to the additional coverage the intervention induced. Our findings thus provide strong empirical support, and the first experimental evidence, for the hypothesis that health insurance coverage reduces mortality.

Our results also speak to important policy questions surrounding the use of outreach strategies to increase health insurance coverage. Ex ante, one might predict that the individuals who choose to forego coverage (absent outreach) would be those for whom the health benefits of coverage tend to be small, especially when the outreach concerns financial penalties for remaining uninsured. However, this is precisely the group that identifies our estimated effect of coverage on mortality. Our results therefore suggest that behavioral frictions like salience or inattention shape how tax incentives interact with adverse selection in health insurance markets. In addition to reducing adverse selection (their typical rationale), outreach efforts of the type we study may yield substantial health benefits.

Although we provide evidence that the pilot intervention reduced mortality, the confidence interval from the two-stage least-squares estimate is consistent with both moderate and very large effects. Combining our findings with results from other research on this topic through meta-analyses, as proposed by Sutton and Abrams (2001), is one path through which future research may succeed in more precisely estimating the causal relationship between coverage and mortality.

An important limitation of our analysis is that our sample period covers only two years of outcome data post-intervention. As a result, our results speak only to the shortterm effects of coverage on mortality. Longer-term mortality effects may be present as 
well. For example, coverage may induce treatment for chronic conditions that would otherwise hasten, but not immediately cause, mortality. Similarly, additional years of outcome data would shed light on the longer-term survival prospects of those whose lives were extended because of the new coverage. Depending on the persistence of the coverage effect, additional years of data could also shed light on the steady-state effects of the new coverage on mortality, as well as on the curvature of the relationship. Although we hope to study these questions in future work as additional data become available, we note that the effective repeal of the individual mandate in 2019 may limit the effect of the pilot on coverage to 2017 and 2018.

Finally, although mortality is an important input into welfare, we lack data on many of the other factors that would enter a careful cost-benefit of outreach, such as financial well-being and health outcomes other than mortality. Along the same lines, because we lack data on health expenditures, we are unable to investigate how the intervention shaped adverse selection in health insurance markets. In future research, we hope to link the pilot study to data that would permit consideration of these questions. 


\section{References}

Abadie, Alberto. 2002. "Bootstrap Tests for Distributional Treatment Effects in Instrumental Variable Models." Journal of the American Statistical Association, 97(457): 284292.

Abaluck, Jason, and Jonathan Gruber. 2011. "Choice Inconsistencies among the Elderly: Evidence from Plan Choice in the Medicare Part D program." American Economic Review, 101(4): 1180-1210.

Abeler, Johannes, and Simon Jäger. 2015. "Complex Tax Incentives." American Economic Journal: Economic Policy, 7(3): 1-28.

Alpert, Abby, Darius Lakdawalla, and Neeraj Sood. 2016. "Prescription Drug Advertising and Drug Utilization: The Role of Medicare Part D."

Angrist, Joshua, and Guido Imbens. 1995. "Two-Stage Least Squares Estimation of Average Causal Effects in Models With Variable Treatment Intensity." Journal of the American Statistical Association.

Aronow, Herbert D, Eric J Topol, Matthew T Roe, Penny L Houghtaling, Katherine E Wolski, A Michael Lincoff, Robert A Harrington, Robert M Califf, E Magnus Ohman, Neal S Kleiman, et al. 2001. "Effect of lipid-lowering therapy on early mortality after acute coronary syndromes: an observational study." The Lancet, 357(9262): 1063-1068.

Auerbach, David, Janet Holtzblatt, Paul Jacobs, Alexandra Minicozzi, Pamela Moomau, and Chapin White. 2010. "Will health insurance mandates increase coverage? Synthesizing perspectives from health, tax, and behavioral economics." National Tax Journal, 63(4): 659.

Baker, David W, Joseph J Sudano, Ramon Durazo-Arvizu, Joseph Feinglass, Whitney P Witt, and Jason Thompson. 2006. "Health insurance coverage and the risk of decline in overall health and death among the near elderly, 1992-2002." Medical care, $277-282$.

Black, Bernard, Alex Hollingsworth, Leticia Nunes, and Kosali Simon. 2019. "The Effect of Health Insurance on Mortality: Power Analysis and What We Can Learn from the Affordable Care Act Coverage Expansions." National Bureau of Economic Research Working Paper 25568.

Borgschulte, Mark, and Jacob Vogler. 2019. "Did the ACA Medicaid Expansion Save Lives?" 
Borusyak, Kirill. 2015. "Bounding the Population Shares Affected by Treatments." SSRN Working Paper 2473827.

Brown, David W, Amanda E Kowalski, and Ithai Z Lurie. Forthcoming. "LongTerm Impacts of Childhood Medicaid Expansions on Outcomes in Adulthood." Review of Economics Studies, , (20835).

Buchmueller, Thomas C., John DiNardo, and Robert G. Valletta. 2011. "The Effect of an Employer Health Insurance Mandate on Health Insurance Coverage and the Demand for Labor: Evidence from Hawaii." American Economic Journal: Economic Policy, 3(4): 25-51.

Cannon, Christopher P, Eugene Braunwald, Carolyn H McCabe, Daniel J Rader, Jean L Rouleau, Rene Belder, Steven V Joyal, Karen A Hill, Marc A Pfeffer, and Allan M Skene. 2004. "Intensive versus moderate lipid lowering with statins after acute coronary syndromes." New England journal of medicine, 350(15): 1495-1504.

Card, David, Carlos Dobkin, and Nicole Maestas. 2008. "The impact of nearly universal insurance coverage on health care utilization: evidence from Medicare." American Economic Review, 98(5): 2242-2258.

Card, David, Carlos Dobkin, and Nicole Maestas. 2009. "Does Medicare Save Lives?" The Quarterly Journal of Economics, 124(2): 597-636.

Chandra, Amitabh, Benjamin Handel, and Joshua Schwartzstein. 2018. "Behavioral Economics and Health-Care Markets." Working Paper.

Chetty, Raj, Adam Looney, and Kory Kroft. 2009. "Salience and Taxation: Theory and Evidence." American Economic Review, 99(4): 1145-77.

Commonwealth Fund. 2017. "Cuts to the ACA's Outreach Budget Will Make It Harder for People to Enroll."

Currie, Janet, and Jonathan Gruber. 1996a. "Health Insurance Eligibility, Utilization of Medical Care, and Child Health*." The Quarterly Journal of Economics, 111(2): 431-466.

Currie, Janet, and Jonathan Gruber. 1996b. "Saving babies: The efficacy and cost of recent changes in the Medicaid eligibility of pregnant women." Journal of political Economy, 104(6): 1263-1296.

Diamond, Rebecca, Michael J Dickstein, Timothy McQuade, and Petra Persson. 2018. "Take-Up, Drop-Out, and Spending in ACA Marketplaces." National Bureau of Economic Research Working Paper 24668. 
Dorn, Stan. 2019. "Maryland's Easy Enrollment Health Insurance Program." Health Affairs Blog.

Escobar, Maria-Luisa, Charles C. Griffin, and R. Paul Shaw. 2011. The impact of health insurance in low-and middle-income countries. Brookings Institution Press.

Finkelstein, Amy, and Robin McKnight. 2008. "What Did Medicare Do? The Initial Impact of Medicare on Mortality and Out of Pocket Medical Spending." Journal of Public Economics, 92(7): 1644-1668.

Finkelstein, Amy, Nathaniel Hendren, and Mark Shepard. 2017. "Subsidizing Health Insurance for Low-Income Adults: Evidence from Massachusetts." Working Paper 23668.

Finkelstein, Amy, Sarah Taubman, Bill Wright, Gruber Jonathan, Joseph P Newhouse, Heidi Allen, Katherine Baicker, and Oregon Health Study Group. 2012. "The Oregon Health Insurance Experiment: Evidence from the First Year." The Quarterly Journal of Economics, 127(3): 1057-1106.

Frean, Molly, Jonathan Gruber, and Benjamin D. Sommers. 2016. "Disentangling the ACA's Coverage Effects: Lessons for Policymakers." New England Journal of Medicine, 375: 1605-1608.

Frean, Molly, Jonathan Gruber, and Benjamin D. Sommers. 2017. "Premium Subsidies, the Mandate, and Medicaid Expansion: Coverage Effects of the Affordable Care Act." Journal of Health Economics, 53: 72-86.

Freed, Salama. 2017. "Insurance Take-Up Among the Near-Elderly in the Age of the Affordable Care Act." Working Paper.

Gallagher, Kelly Sims, and Erich Muehlegger. 2011. "Giving green to get green? Incentives and consumer adoption of hybrid vehicle technology." Journal of Environmental Economics and Management, 61(1): 1-15.

Giedion, Ursula, Eduardo Andres Alfonso, and Yadira Diaz. 2013. "The Impact of Universal Coverage Schemes in the Developing World: A Review of the Existing Evidence." The World Bank.

Gill, Dee. 2018. "Researchers find common warning signs in persuasion projects that went wrong." UCLA Anderson Review.

Goodman-Bacon, Andrew. 2018. "Public insurance and mortality: evidence from Medicaid implementation." Journal of Political Economy, 126(1): 216-262. 
Hackmann, Martin B., Jonathan T. Kolstad, and Amanda E. Kowalski. 2015. "Adverse Selection and an Individual Mandate: When Theory Meets Practice." American Economic Review, 105(3): 1030-1066.

Handel, Benjamin R. 2013. "Adverse Selection and Inertia in Health Insurance Markets: When Nudging Hurts.” American Economic Review, 103(7): 2643-82.

Handel, Benjamin R., and Jonathan T. Kolstad. 2015. "Health Insurance for "Humans": Information Frictions, Plan Choice, and Consumer Welfare." American Economic Review, 105(8): 2449-2500.

Handel, Benjamin R., Jonathan T. Kolstad, and Johannes Spinnewijn. 2018. "Information Frictions and Adverse Selection: Policy Interventions in Health Insurance Markets." Review of Economics and Statistics.

Heim, Brad, I. Z. Lurie, and Daniel Sacks. 2019. "Does the individual mandate affect insurance coverage? Regression kink evidence from the population of tax returns." Working Paper.

Institute of Medicine. 2002. Care without coverage: Too little, too late. National Academy Press.

Khatana, Sameed Ahmed M, Anjali Bhatla, Ashwin S Nathan, Jay Giri, Changyu Shen, Dhruv S Kazi, Robert W Yeh, and Peter W Groeneveld. 2019. "Association of medicaid expansion with cardiovascular mortality." JAMA cardiology.

Kronick, Richard. 2009. "Health insurance coverage and mortality revisited." Health services research, 44(4): 1211-1231.

Levitis, Jason A. 2018. "State Individual Mandates." Center for Health Policy at Brookings Report.

Levy, Helen, and David Meltzer. 2008. "The impact of health insurance on health." Annu. Rev. Public Health, 29: 399-409.

Loewenstein, George, Joelle Y. Friedman, Barbara McGill, Sarah Ahmad, Suzanne Linck, Stacey Sinkula, John Beshears, James J. Choi, Jonathan Kolstad, and David Laibson. 2013. "Consumers' Misunderstanding of Health Insurance." Journal of Health Economics, 32(5): 850-862.

Lurie, Ithai, and James Pearce. 2019. "Health Insurance Coverage from Administrative Tax Data." Treasury Working Paper. 
Lurie, Ithai Z, and Janet McCubbin. 2016. "What Can Tax Data Tell Us about the Uninsured? Evidence from 2014." National Tax Journal, 69(4): 883.

Medford-Davis, Laura N., Gregg C. Fonarow, Deepak L. Bhatt, Deepak L. Xu, Eric E. Smith, Robert Suter, Eric D. Peterson, Ying Xian, Roland A. Matsouaka, and Lee H. Schwamm. 2016. "Impact of Insurance Status on Outcomes and Use of Rehabilitation Services in Acute Ischemic Stroke: Findings From Get With The Guidelines-Stroke." Journal of the American Heart Association, 5(11).

Meyer, Bruce D, and Laura R Wherry. 2012. "Saving Teens: Using a Policy Discontinuity to Estimate the Effects of Medicaid Eligibility." National Bureau of Economic Research Working Paper 18309.

Michalopoulos, Charles, David Wittenburg, Dina Israel, Jennifer Schore, Anne Warren, Aparajita Zutshi, Stephen Freedman, and Lisa Schwarts. 2011. "The Accelerated Benefits Demonstration and Evaluation Project: Impacts on Health and Employment at Twelve Months , Volume 1."

Miller, Sarah, Sean Altekruse, Norman Johnson, and Laura R. Wherry. 2019. "Medicaid and Mortality: New Evidence from Linked Survey and Administrative Data." Working Paper.

Newhouse, Joseph P, and the Insurance Experiment Group. 1993. Free for All?: Lessons from the RAND Health Insurance Experiment. MAHarvard University Press.

Newhouse, Joseph P, et al. 1993. Free for all? Harvard University Press.

Phillip, Levine; Robin McKnight, and Samantha Heep. 2011. "How Effective are Public Policies to Increase Health Insurance Coverage among Young Adults?" American Economic Journal: Economic Policy, 3(1): 129-156.

Phillips, Kristine. 2017. “Nobody dies because they don't have access to health care,' GOP lawmaker says. He got booed." Washington Post.

Safdar, Basmah, Judith H. Lichtman, and Gail D'Onofrio. 2012. "Sex and the CT: An Evolving Story of the Heart." Academic Emergency Medicine, 19(2): 197-200.

Smolderen, Kim, John Spertus, Brahmajee K. Nallamothu, Harlan M. Krumholz, Fengming Tang, Joseph S. Ross, Henry H. Ting, Karen P. Alexander, Saif S. Rathore, and Paul S. Chan. 2010. "Health Care Insurance, Financial Concerns, and Delays to Hospital Presentation in Acute Myocardial Infarction." JAMA, 303(14): 1392-1400. 
Sommers, Benjamin D, Katherine Baicker, and Arnold M Epstein. 2012. "Mortality and Access to Care among Adults after State Medicaid Expansions." New England Journal of Medicine, 367(11): 1025-1034.

Sommers, Benjamin D, Sharon K Long, and Katherine Baicker. 2014. "Changes in Mortality after Massachusetts Health Care Reform: a Quasi-Experimental Study." Annals of Internal Medicine, 160(9): 585-593.

Sutton, Alex J, and Keith R Abrams. 2001. "Bayesian methods in meta-analysis and evidence synthesis." Statistical Methods in Medical Research, 10(4): 277-303. PMID: 11491414.

Swaminathan, Shailender, Benjamin D Sommers, Rebecca Thorsness, Rajnish Mehrotra, Yoojin Lee, and Amal N Trivedi. 2018. "Association of Medicaid expansion with 1-year mortality among patients with end-stage renal disease." Jama, 320(21): 2242-2250.

Weathers, Robert R, II, and Michelle Stegman. 2012. "The Effect of Expanding Access to Health Insurance on the Health and Mortality of Social Security Disability Insurance Beneficiaries." Journal of Health Economics, 31(6): 863-875.

Woolhandler, Steffie, and David U Himmelstein. 2017. "The Relationship of Health Insurance and Mortality: Is Lack of Insurance Deadly?" Annals of internal medicine, 167(6): 424-431. 
Figure 1: Coverage Rates by Month

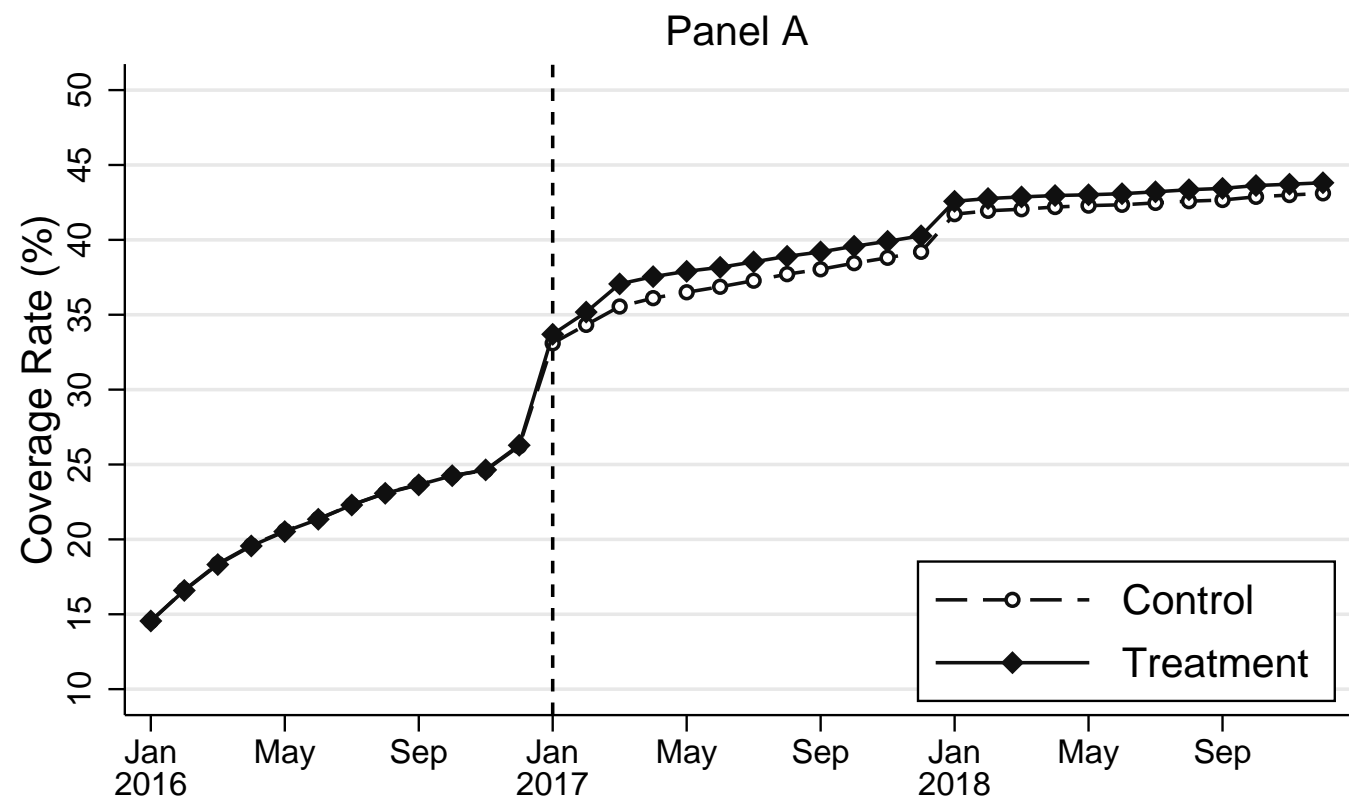

Panel B

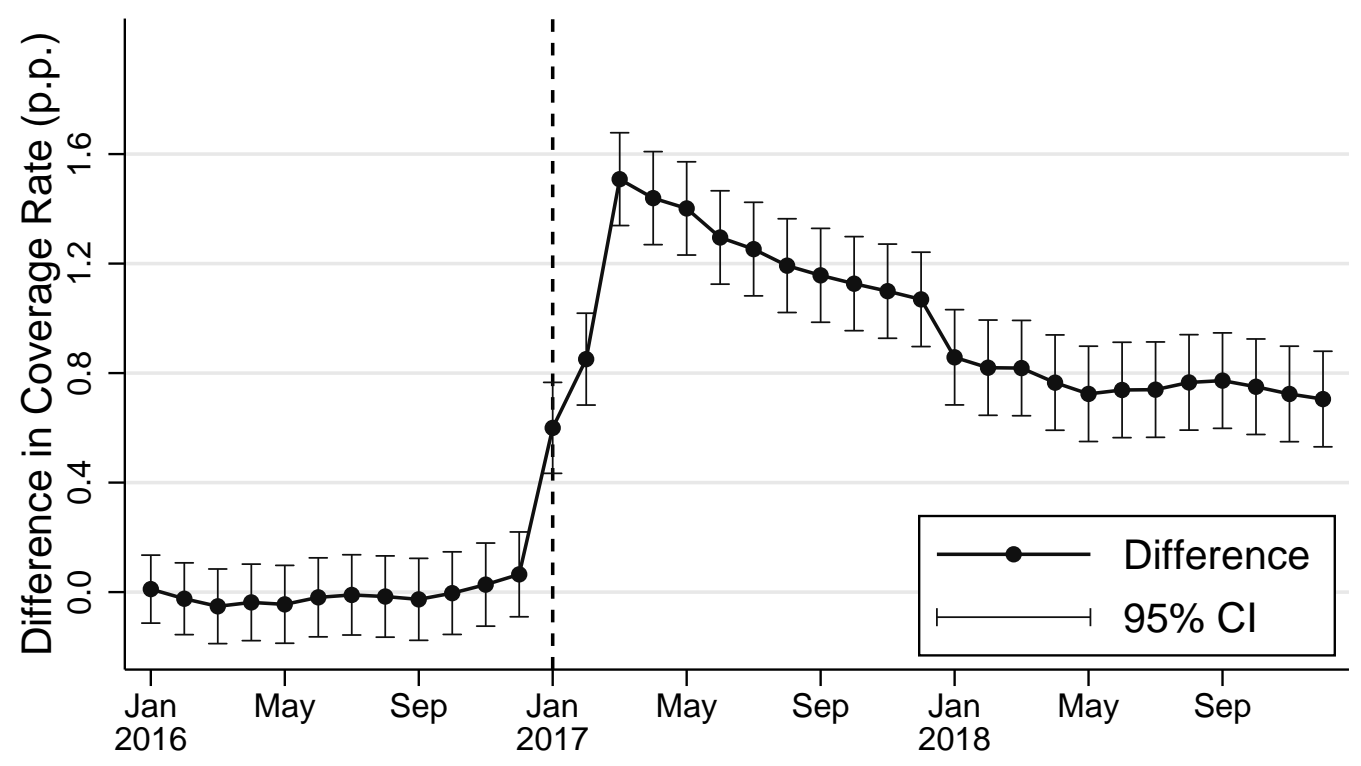

Notes: Panel A displays the shares of the treatment and control group enrolled in any coverage in the specified month. Panel B displays the difference in the share between the treatment and control groups enrolled in any coverage in the specified month. Units are percentage points $(0-100)$. Both panels exclude individuals with full coverage in January through November of 2016. Brackets denote the $95 \%$ confidence interval based on standard errors that are clustered by household. 
Figure 2: Effect of Intervention on Number of Covered Months in 2017

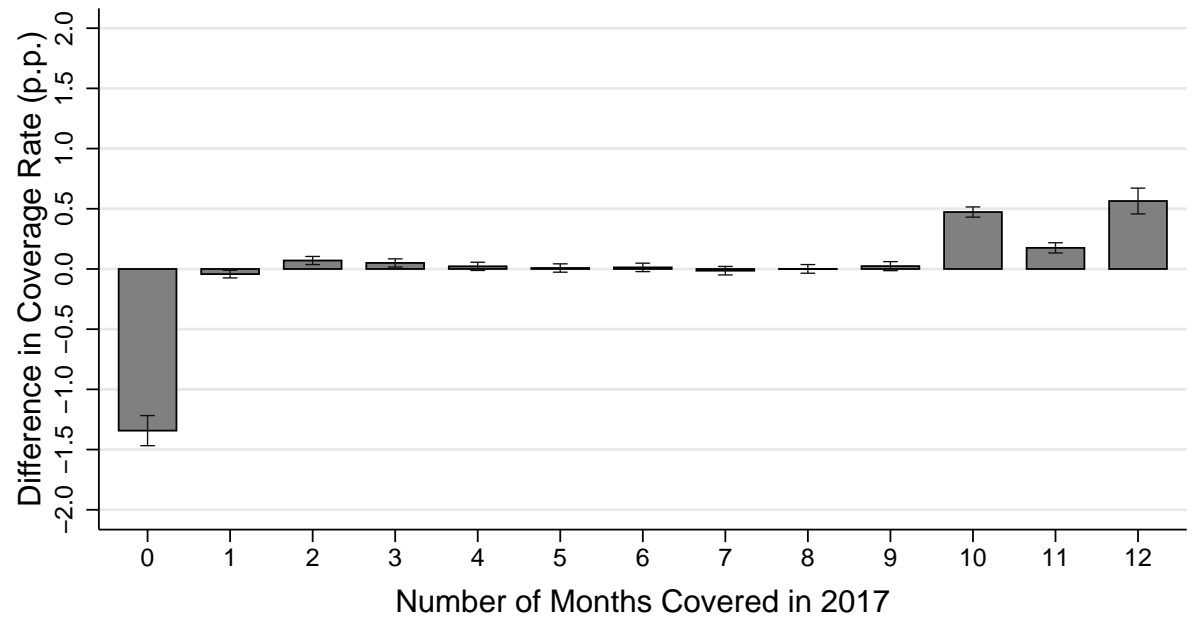

Notes: The figure denotes the difference between the treatment and control groups in the share of individuals who enroll in the specified number of months of 2017 coverage. The vertical axis units are percentage points $(0-100)$. Positive values indicate more individuals were enrolled in the specified number of months of coverage in the treatment group relative to the control group. The analysis excludes individuals with full coverage in January through November of 2016.

Brackets denote the $95 \%$ confidence interval based on standard errors that are clustered by. household. 
Figure 3: Mortality Over Time by Treatment Group
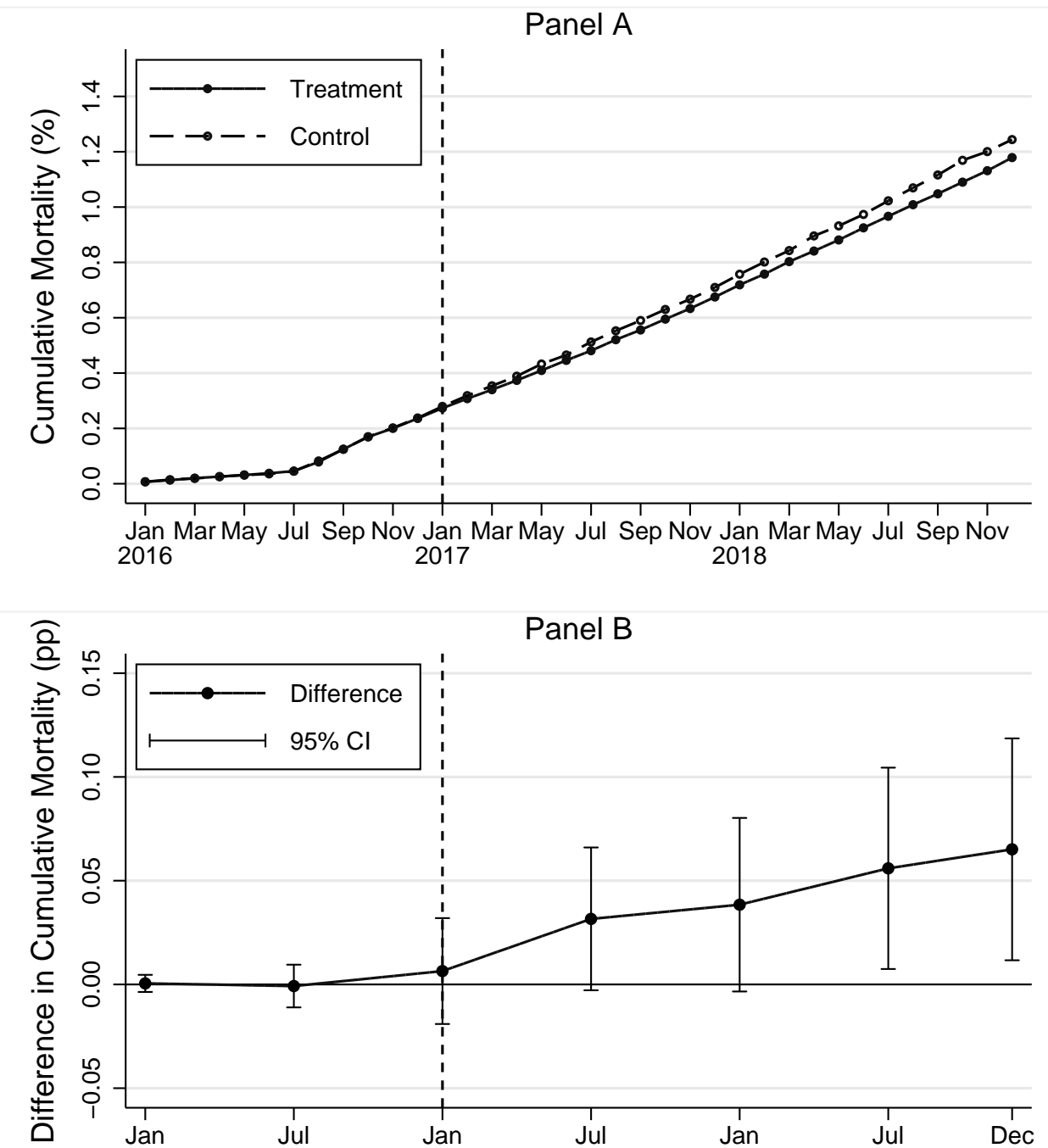

Panel B

Notes: Panel A displays the share of individuals that died during or prior to the specified date. Panel $B$ displays the difference in the cumulative mortality rate between the control and treatment groups. Units are percentage points $(0-100)$. The difference is calculated at six-month intervals that extend through the end of the specified month. Brackets denote the $95 \%$ confidence interval based on standard errors that are clustered by household. Both panels are limited to individuals between the ages of $45-64$ at the start of 2017 and exclude individuals with full coverage in January through November of 2016. 
Figure 4: Mortality Effect by Age

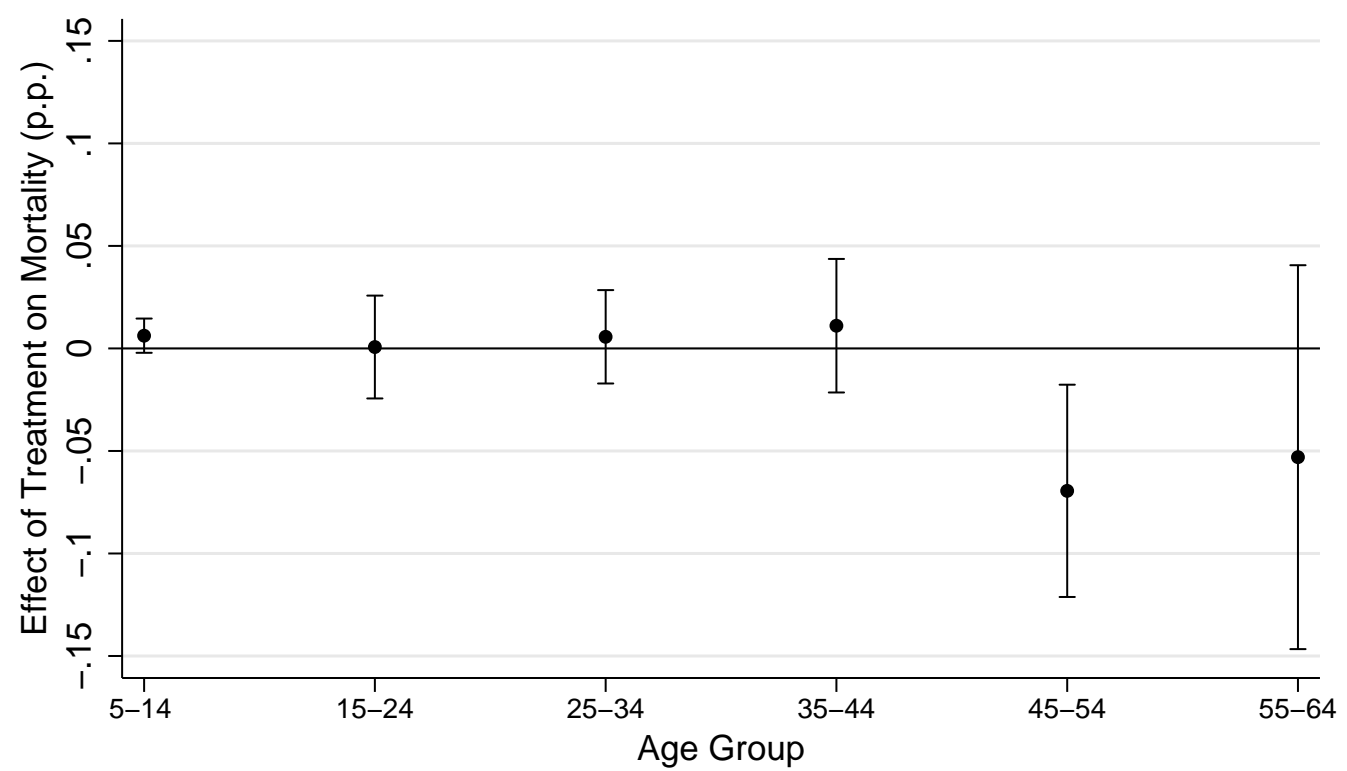

Notes: The figure displays the estimated effect of the intervention on 2017-18 mortality for individua in the specified age ranges. Units are percentage points $(0-100)$. Ages are calculated the start of 2017. Brackets denote the $95 \%$ confidence interval based on standard errors that are clustered bj household. The analysis excludes individuals with full coverage in January through November of 2016. 
Table 1: Summary Statistics and Balance Checks

\begin{tabular}{|c|c|c|c|c|c|c|}
\hline & $(1)$ & $(2)$ & (3) & $(4)$ & $(5)$ & (6) \\
\hline & All & No Full- & \multicolumn{4}{|c|}{ Experimental Sample } \\
\hline & Taxpayers & $\begin{array}{c}\text { Year } \\
\text { Coverage }\end{array}$ & All & Treatment & Control & $\begin{array}{c}\text { Difference } \\
\text { p-value }\end{array}$ \\
\hline \multicolumn{7}{|l|}{ Individual characteristics } \\
\hline Female & 0.511 & 0.478 & 0.451 & 0.450 & 0.451 & 0.669 \\
\hline Age & 38.6 & 34.5 & 31.1 & 31.1 & 31.1 & 0.395 \\
\hline $0-18$ & 0.239 & 0.265 & 0.271 & 0.271 & 0.271 & 0.374 \\
\hline $19-26$ & 0.111 & 0.128 & 0.136 & 0.136 & 0.136 & 0.756 \\
\hline $27-45$ & 0.242 & 0.290 & 0.349 & 0.349 & 0.349 & 0.681 \\
\hline $45-64$ & 0.261 & 0.230 & 0.230 & 0.230 & 0.230 & 0.977 \\
\hline 65 or older & 0.147 & 0.087 & 0.015 & 0.015 & 0.014 & 0.510 \\
\hline \multicolumn{7}{|l|}{ Household characteristics } \\
\hline Married & 0.554 & 0.450 & 0.414 & 0.414 & 0.414 & 0.860 \\
\hline Household income & 78,534 & 30,159 & 42,710 & 42,699 & 42,783 & 0.349 \\
\hline Income/Federal Poverty Line & 4.16 & 1.61 & 2.35 & 2.35 & 2.36 & 0.523 \\
\hline$<1.38$ & 0.366 & 0.657 & 0.267 & 0.267 & 0.266 & 0.143 \\
\hline $1.38-4.00$ & 0.276 & 0.228 & 0.629 & 0.629 & 0.630 & 0.429 \\
\hline$\geq 4.00$ & 0.358 & 0.115 & 0.104 & 0.103 & 0.104 & 0.313 \\
\hline Household size & 2.81 & 2.86 & 2.74 & 2.74 & 2.74 & 0.725 \\
\hline \multicolumn{7}{|l|}{ Local characteristics } \\
\hline High school degree or higher & 0.866 & 0.835 & 0.835 & 0.835 & 0.835 & 0.546 \\
\hline BA degree or higher & 0.299 & 0.264 & 0.249 & 0.249 & 0.249 & 0.331 \\
\hline Expansion state & 0.618 & 0.523 & 0.560 & 0.560 & 0.560 & 0.819 \\
\hline State-based marketplace & 0.344 & 0.288 & 0.222 & 0.222 & 0.222 & 0.637 \\
\hline \multicolumn{7}{|l|}{ Penalty } \\
\hline Claimed 2014 exemption & 0.088 & 0.307 & 0.175 & 0.176 & 0.174 & 0.010 \\
\hline Paid 2014 penalty & 0.055 & 0.196 & 0.425 & 0.425 & 0.425 & 0.765 \\
\hline 2014 penalty if penalized & 247 & 246 & 257 & 257 & 258 & 0.182 \\
\hline Claimed 2015 exemption & 0.076 & 0.443 & 0.063 & 0.063 & 0.063 & 0.138 \\
\hline Paid 2015 penalty & 0.048 & 0.300 & 1.000 & 1.000 & 1.000 & . \\
\hline 2015 penalty if penalized & 545 & 546 & 528 & 528 & 529 & 0.268 \\
\hline Projected 2017 annualized penalty & 2,109 & 1,599 & 1,526 & 1,526 & 1,526 & 0.944 \\
\hline \multicolumn{7}{|l|}{2015 coverage } \\
\hline Any coverage & 0.863 & 0.594 & 0.583 & 0.583 & 0.583 & 0.287 \\
\hline Covered months & 9.80 & 5.88 & 5.28 & 5.28 & 5.27 & 0.340 \\
\hline Full-year coverage & 0.745 & 0.356 & 0.282 & 0.282 & 0.281 & 0.677 \\
\hline \multicolumn{7}{|l|}{2016 coverage } \\
\hline Any coverage & 0.879 & 0.631 & 0.642 & 0.642 & 0.642 & 0.272 \\
\hline Covered months & 10.23 & 6.94 & 6.62 & 6.62 & 6.61 & 0.101 \\
\hline Full-year coverage & 0.778 & 0.457 & 0.419 & 0.419 & 0.418 & 0.049 \\
\hline \multicolumn{7}{|l|}{ Observations } \\
\hline Individuals & $2,893,655$ & $45,472,192$ & $8,897,821$ & $7,651,401$ & $1,246,420$ & \\
\hline Households & $1,398,008$ & $22,778,960$ & $4,526,719$ & $3,892,849$ & 633,870 & \\
\hline
\end{tabular}

Notes: The table presents summary statistics for a $1 \%$ random sample of 2015 tax returns (column 1), the set of 2015 tax returns that did not report full-year coverage (column 2), and the experimental sample (columns 3-5). Column 6 reports the p-value for the test of equality between the treatment and control groups, with standard errors clustered by household. All statistics are calculated at the individual level. Local characteristics are imputed based on the zip code corresponding to the individual's 2015 tax return. Households correspond to the individuals listed on a tax return. 
Table 2: Coverage Effect by Prior-Year Coverage

\begin{tabular}{|c|c|c|c|c|c|c|}
\hline & (1) & $(2)$ & $(3)$ & (4) & $(5)$ & (6) \\
\hline & Full & \multicolumn{4}{|c|}{ Months of 2016 coverage } & \\
\hline & Sample & 0 & $1-5$ & $6-10$ & 11 & $<11$ \\
\hline Treated & $\begin{array}{c}0.849 \\
(0.056)\end{array}$ & $\begin{array}{c}1.831 \\
(0.084)\end{array}$ & $\begin{array}{c}0.925 \\
(0.162)\end{array}$ & $\begin{array}{c}0.306 \\
(0.110)\end{array}$ & $\begin{array}{c}0.076 \\
(0.033)\end{array}$ & $\begin{array}{c}1.343 \\
(0.078)\end{array}$ \\
\hline Control mean & 68.523 & 27.394 & 76.636 & 86.213 & 96.602 & 47.557 \\
\hline Observations & $8,893,653$ & $3,222,566$ & 738,259 & $1,123,340$ & $3,809,488$ & $5,084,165$ \\
\hline
\end{tabular}

Table 3: Coverage Effect by Type of Coverage

\begin{tabular}{lcccccc}
\hline & $(1)$ & $(2)$ & $(3)$ & $(4)$ & $(5)$ & $(6)$ \\
\cline { 2 - 7 } & Exchange & Medicaid & ESI & Off-Exchange & VA & Medicare \\
\hline \hline Treated & 1.021 & 0.445 & 0.076 & 0.016 & 0.021 & 0.011 \\
& $(0.030)$ & $(0.062)$ & $(0.071)$ & $(0.015)$ & $(0.006)$ & $(0.011)$ \\
\hline Control mean & 3.436 & 18.595 & 27.278 & 0.971 & 0.184 & 0.694 \\
Observations & $5,084,165$ & $5,084,165$ & $5,084,165$ & $5,084,165$ & $5,084,165$ & $5,084,165$ \\
\hline
\end{tabular}

Notes: Outcome indicates enrollment in one month or more of the specified coverage during 2017. Units are percentage points (0-100). ESI refers to employer-sponsored coverage. Off-Exchange refers to individual coverage not purchased through the Exchange. VA refers to coverage provided through the Veterans Administration. All columns exclude individuals with full coverage in January through November of 2016. Standard errors, reported in parentheses, are clustered by household.

Table 4: Coverage Effect by Age

\begin{tabular}{lccccc}
\hline & $(1)$ & $(2)$ & $(3)$ & $(4)$ & $(5)$ \\
\cline { 2 - 6 } & $0-18$ & $19-26$ & $27-44$ & $45-64$ & $65+$ \\
\hline \hline Treated & 0.843 & 1.174 & 1.154 & 2.063 & 0.622 \\
& $(0.207)$ & $(0.170)$ & $(0.106)$ & $(0.131)$ & $(0.640)$ \\
\hline Control mean & 59.705 & 51.706 & 47.692 & 37.528 & 52.378 \\
Observations & 817,915 & 753,088 & $2,094,777$ & $1,358,983$ & 59,365 \\
\hline
\end{tabular}

Notes: Outcome indicates any 2017 coverage. Units are percentage points (0-100). Columns restrict to individuals with ages in the specified bins at the start of 2017 . All columns exclude individuals with full coverage in January through November of 2016. Standard errors, reported in parentheses, are clustered by household. 
Table 5: Coverage Effect by Income

\begin{tabular}{lcccc}
\hline & $(1)$ & $(2)$ & $(3)$ & $(4)$ \\
\cline { 2 - 5 } & \multicolumn{4}{c}{ Income/FPL Percentage } \\
\cline { 2 - 5 } & $0-100$ & $100-138$ & $138-400$ & $400+$ \\
\hline \hline Treated & 1.121 & 2.287 & 1.403 & 0.391 \\
& $(0.183)$ & $(0.219)$ & $(0.102)$ & $(0.225)$ \\
\hline Control mean & 47.847 & 48.510 & 47.782 & 45.382 \\
Observations & 879,457 & 638,779 & $2,934,527$ & 616,667 \\
\hline
\end{tabular}

Notes: Outcome indicates any 2017 coverage. Units are percentage points (0-100). Columns restrict to individuals based on 2016 household income as a percentage of the federal poverty line. All columns exclude individuals with full coverage in January through November of 2016. Standard errors, reported in parentheses, are clustered by household.

Table 6: Bounds on Responder Share and Intensive Margin Treatment Effect

\begin{tabular}{|c|c|c|c|c|c|c|}
\hline & (1) & $(2)$ & $(3)$ & $(4)$ & $(5)$ & (6) \\
\hline & & $\begin{array}{l}\text { Lower Bound } \\
\text { for Responder } \\
\text { Share }\end{array}$ & $\begin{array}{l}\text { Upper Bound } \\
\text { for Responder } \\
\text { Share }\end{array}$ & & $\begin{array}{l}\text { Lower Bound } \\
\text { for Responder } \\
\text { Share }\end{array}$ & $\begin{array}{l}\text { Upper Bound } \\
\text { for Responder } \\
\text { Share }\end{array}$ \\
\hline & \multicolumn{3}{|c|}{2017 Coverage } & \multicolumn{3}{|c|}{ 2017-18 Coverage } \\
\hline $\begin{array}{l}\text { Overall Effect, } \\
E\left[C_{i}(1)-C_{i}(0)\right]\end{array}$ & 0.140 & 0.140 & 0.140 & 0.232 & 0.232 & 0.232 \\
\hline $\begin{array}{l}\text { Share Responders, } \\
\operatorname{Pr}\left[C_{i}(1)>C_{i}(0)\right] \\
\text { Effect for Responders, } \\
E\left[C_{i}(1)-C_{i}(0) \mid C_{i}(1)>C_{i}(0)\right]\end{array}$ & & 10.001 & 0.140 & & 19.672 & 0.232 \\
\hline
\end{tabular}

Notes: Columns 1-3 provide outcomes for coverage in 2017; Columns 4-6 provide outcomes for coverage during 2017 and 2018. Columns 2 and 5 provide lower bounds for the share of individuals who increase coverage in response to the treatment following Borusyak (2015), and corresponding intensive margin effects. Columns 3 and 6 provide upper bounds for the share of respondents and corresponding intensive margin effects, assuming monotonicity and following the method described in the body of the paper. Units for Rows 1 and 3 are months of coverage. Units for Row 2 are population shares (0-1.00). All columns exclude individuals with full coverage in January through November of 2016. 
Table 7: Effect of Intervention on Mortality

\begin{tabular}{lcccc}
\hline & $(1)$ & $(2)$ & $(3)$ & $(4)$ \\
\cline { 2 - 4 } Mortality & $\begin{array}{c}\text { Mortality } \\
\text { (Controls) }\end{array}$ & $\begin{array}{c}\text { Prior-Year } \\
\text { Mortality }\end{array}$ & $\begin{array}{c}\text { Mortality Among } \\
\text { Prior-Year Insured }\end{array}$ \\
\hline \hline Treated & -0.063 & -0.061 & -0.002 & -0.010 \\
& $(0.025)$ & $(0.025)$ & $(0.012)$ & $(0.037)$ \\
\hline Control Mean & 1.007 & 0.993 & 0.238 & 1.143 \\
Observations & $1,358,983$ & $1,309,736$ & $1,358,983$ & 688,795 \\
\hline Notes: Outcome indicates whether an individual died during 2017-18. Units are \\
percentage points (0-100). Columns 1-3 exclude individuals with full coverage in \\
January through November of 2016. Column 4 is limited to individuals with full coverage \\
in January through November of 2016. The specification reported in Column 2 controls \\
for age fixed effects, gender, marital status, 2016 insurance coverage, 2016 household \\
income relative to the federal poverty line, mean 2016 state-level mortality, \\
and logged zipcode-level controls for median income, share of Spanish speakers, \\
and share of college graduates. All columns are limited to individuals between \\
the ages of 45-64 at the start of 2017. Standard errors, reported in parentheses, \\
are clustered by household.
\end{tabular}

Table 8: Effect of Coverage on Mortality

\begin{tabular}{lccccc}
\hline & \multicolumn{1}{c}{$(1)$} & $(2)$ & $(3)$ & $(4)$ & $(5)$ \\
\cline { 2 - 6 } & $\begin{array}{c}\text { Mortality } \\
\text { (OLS) }\end{array}$ & $\begin{array}{c}\text { Covered Months } \\
\text { (First Stage) }\end{array}$ & $\begin{array}{c}\text { Mortality } \\
\text { (2SLS) }\end{array}$ & $\begin{array}{c}\text { Mortality } \\
\text { (2SLS) }\end{array}$ & $\begin{array}{c}\text { Mortality } \\
\text { (2SLS, no prior- } \\
\text { year exclusion) }\end{array}$ \\
\hline \hline Covered Months & -0.026 & & -0.178 & -0.166 & -0.167 \\
Treated & $(0.001)$ & 0.358 & $(0.070)$ & $(0.068)$ & $(0.068)$ \\
& & $(0.026)$ & & & \\
Controls & & & & $\times$ & 1.040 \\
Control mean & 1.007 & 7.795 & 1.007 & 0.993 & $1,983,167$ \\
Observations & $1,358,983$ & $1,358,983$ & $1,358,983$ & $1,309,736$ & \\
\hline
\end{tabular}

Notes: Columns 1, 3, 4, and 5: outcome indicates whether an individual died during 2017-18; units are percentage points (0-100). Column 2: outcome is months of 2017-18 coverage. Columns 1-4 exclude individuals with full coverage in January through November of 2016 . Columns 4 and 5 control for age fixed effects, gender, marital status, no 2016 insurance coverage, 2016 household income relative to the federal poverty line, mean 2016 state-level mortality, and logged zipcode-level controls for median income, share of Spanish speakers, and share of college graduates. Column 5 additionally controls for having full coverage in January through November of 2016 and includes as an instrument an interaction of this variable with the treatment group indicator. All columns are limited to individuals between the ages of 45-64 at the start of 2017. Standard errors, reported in parentheses, are clustered by household. 
Table 9: Characteristics by Complier Status

\begin{tabular}{lcccc}
\hline & $(1)$ & $(2)$ & $(3)$ & $(4)$ \\
\cline { 2 - 5 } & Overall & Compliers & Always-Takers & Never-Takers \\
\hline Share of Population & 1.000 & 0.021 & 0.375 & 0.604 \\
Prior Coverage & & & & \\
$\quad$ Any 2015 Coverage & 0.243 & 0.137 & 0.407 & 0.145 \\
$\quad$ Months of 2015 Coverage & 1.596 & 1.035 & 2.736 & 0.907 \\
$\quad$ Any 2016 Coverage & 0.262 & 0.078 & 0.576 & 0.074 \\
$\quad$ Months of 2016 Coverage & 1.597 & 0.264 & 3.620 & 0.385 \\
Demographic Characteristics & & & & 53.401 \\
$\quad$ Age & 53.223 & 53.753 & 52.906 & 0.593 \\
$\quad$ Male & 0.577 & 0.556 & 0.552 & 2.640 \\
$\quad$ Income & 2.650 & 2.181 & 2.693 & 0.004 \\
Baseline Mortality & & & & 0.007 \\
$\quad$ Baseline Mortality in 2017 & & 0.007 & & \\
$\quad$ Baseline Mortality in 2017-18 & & 0.014 & & \\
\hline
\end{tabular}

Notes: Compliers are defined as individuals who enroll in positive months of 2017 coverage when assigned to the treatment but not when assigned to the control. Always-takers enroll in positive months of 2017 coverage regardless of treatment assignment. Never-takers enroll in zero months of 2017 coverage regardless of treatment assignment. Coverage variables for 2016 refer to coverage during the first 11 months of 2016. Baseline mortality in 2017 refers to the mean 2017 death rate of individuals with zero months of 2017 coverage. Baseline mortality in 2017-18 is calculated as twice the baseline mortality in 2017. All columns are limited to individuals between the ages of 45-64 at the start of 2017 and exclude individuals with full coverage in January through November of 2016. 


\section{Appendix}

Figure A.1: Letters

(a) Baseline

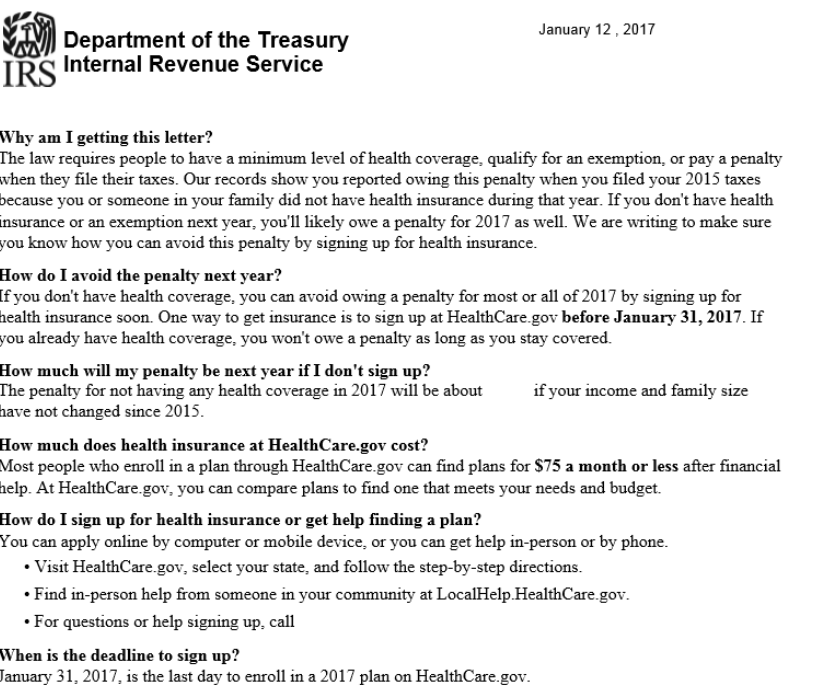

(c) Non-Personalized

Department of the Treasury

IRS Internal Revenue Service

January 12,2017

Why am I getting this letter?

The law requires most people to have a minimum level of health coverage, qualify for an exemption, or pay a penalty when they file their taxes. Our records show you reported owing this penalty when you filed your 20 taxes because you or someone in your family did not have health insurance during that year. If you don't have health insurance or an exemption next year, you'll likely owe a penalty for 2017 as well. We are writing to make by signing up for health insuran

How do I avoid the penalty next year?

If you don't have health coverage, you can avoid owing a penalty for most or all of 2017 by signing up for health insurance soon. One way to get insurance is to sign up at HealthCare.gov before January 31, 2017. If you already have health coverage, you won't owe a penalty as long as you stay covered

How much will my penalty be next year if I don't sign up?

The penalty for not having any health coverage in 2017 will be at least $\$ 695$ per adult and $\$ 347$ per child (up to $\$ 2,085$ per family), and could be more, depending on your income.

How much does health insurance at HealthCare.gov cost? help. At HealthCare.gov, you can compare plans to find one that meets your needs and budget.

How do I sign up for health insurance or get help finding a plan?

You can apply online by computer or mobile device, or you can get help in-person or by phone.

- Visit HealthCare.gov, select your state, and follow the step-by-step directions.

- Find in-person help from someone in your community at LocalHelp.HealthCare.gov

- For questions or help signing up, call

When is the deadline to sign up?

January 31.2017, is the last day to enroll in a 2017 plan on HealthCare gov. (b) Exemption Information

January 12, 2017
IRS Internal Revenue Service

Why am I getting this letter?

The law requires most people to have a minimum level of health coverage, qualify for an exemption, or pay a penalty when they file their taxes. Our records show you reported owing this penalty when you filed your 2015 taxes because you or someone in your family did not have health insurance during that year. If you don't have health insurance or an exemption next year, you'll likely owe a penalty for 2017 as well. We are writing to make sure you know how you can avoid this penalty by signing up for health insurance.

How do I avoid the penalty next year?

If you don't have health coverage, you can avoid owing a penalty for most or all of 2017 by signing up for health insurance soon. One way to get insurance is to sign up at HealthCare.gov before January 31, 2017. If to avoid the penalty by applying for an exemption at HealthCare.gov or by claiming an exemption on your 2017 taxes.

How much will my penalty be next year if $I$ don't sign up?

The penalty for not having any health coverage in 2017 will be about have not changed since 2015 .

How much does health insurance at HealthCare.gov cost?

cor $\$ 75$ a month or less after financis help. At HealthCare.gov, you can compare plans to find one that meets your needs and budget.

How do I sign up for health insurance or get help finding a plan?

You can apply online by computer or mobile device, or you can get help in-person or by phone.

Visit HealthCare.gov, select your state, and follow the step-by-step directions

Find in-person help from someone in your community at LocalHelp.HealthCare.gov.

For questions or help signing up, call

When is the deadline to sign up?

January 31,2017 , is the last day to enroll in a 2017 plan on HealthCare.gov.

(d) Spanish

¿Por qué recibo esta carta?

La ley le requiere a la mayoría de las personas tener un nivel mínimo de cobertura médica, calificar para una exención o pagar una multa al presentar sus impuestos. Nuestros registros muestran que usted informó adeudar esta multa cuando presento sus impuestos del ano 2015 , porque usted o alguien en su familia no tuvo el seguro médico durante ese año. Si usted no tiene el seguro médico o una exención el próximo año, es probable que ambién adeude una multa para 2017. Le escribimos para asegurar que ustod sabe cómo puede evitar esta multa

Cómo puedo evitar la multa el próximo año

Si usted no tiene la cobertura médica, puede evitar adeudar una multa para la mayor parte o la totalidad del año 2017 inscribiéndose cuanto antes a un seguro médico. Una manera de obtener un seguro, es inscribirse en CuidadoDeSalud.gov antes del 31 de enero de 2017. Si ya tiene la cobertura médica, usted no adeudará una multa siempre y cuando mantenga su cobertura.

Cuánto será mi multa el próximo año si no me inscribo?
La multa en el año 2017 por no tener ninguna cobertura de salud, será aproximadamente si sus ingresos y el tamaño de su familia no han cambiado desde 2015 .

¿Cuánto cuesta el seguro médico en CuidadoDeSalud.gov?

La mayoria de las personas que se inscriben en un plan a través de CuidadoDeSalud gov, pueden encontrar planes de $\mathbf{S 7 5}$ o menos al mes, después de la ayuda financiera. En CuidadoDeSalud.gov, puede comparar los planes para encontrar uno que se ajuste a sus necesidades y presupuesto.

¿Cómo me inscribo a un seguro médico u obtengo ayuda para encontrar un plan?

Puede solicitar en linea por computadora o un dispositivo móvil, o puede obtener ayuda en persona o por

- Visite CuidadoDeSalud.gov, seleccione su estado y siga las instrucciones paso a paso.

- Encuentre ayuda en persona de alguien en su comunidad, en LocalHelp.HealthCare.go

- Para preguntas o ayuda para inscribirse, llame al (usuarios de TTY:

Cuíndo es la fecha límite para inscribirse?

El 31 de enero de 2017 es el último dia para inscribirse en un plan para 2017, en CuidadoDeSalud gov. 
Figure A.2: Coverage Rate Effect by Month by Coverage Type

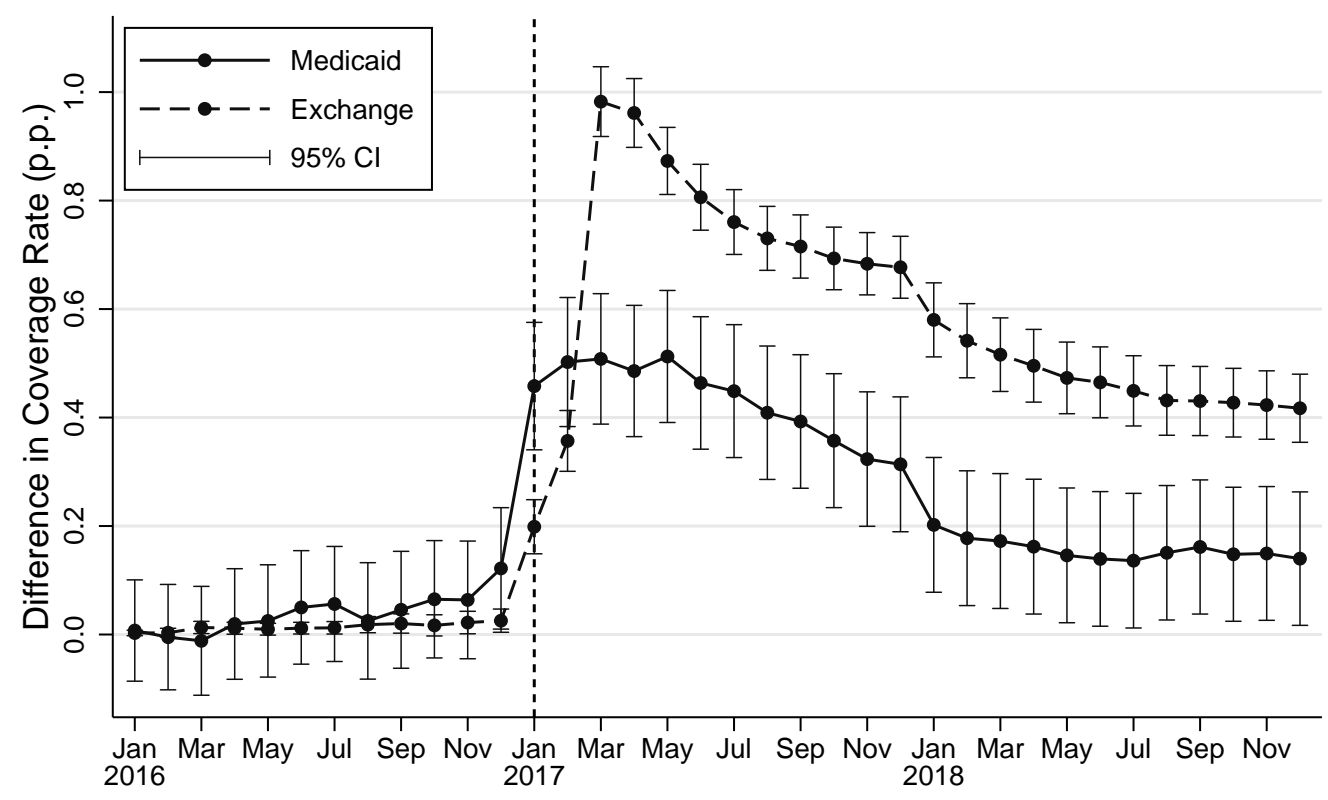

Notes: The figure displays the difference in the share of the treatment and control groups enrolled in Medicaid and Exchange coverage in the specified month. Units are percentage points $(0-100)$. The figure excludes individuals with full coverage in January through November of 2016. Brackets denote the $95 \%$ confidence interval based on standard errors that are clustered by household. 
Figure A.3: Probability of Detecting Mortality Effect by Age Range
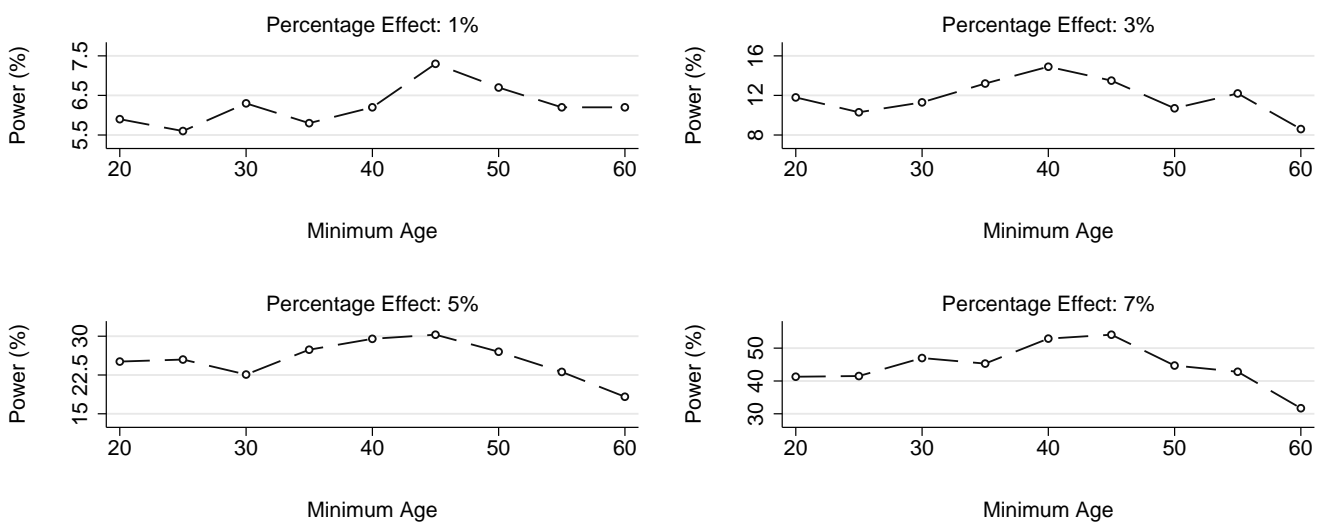

Uninsured Complier Scalar: 2
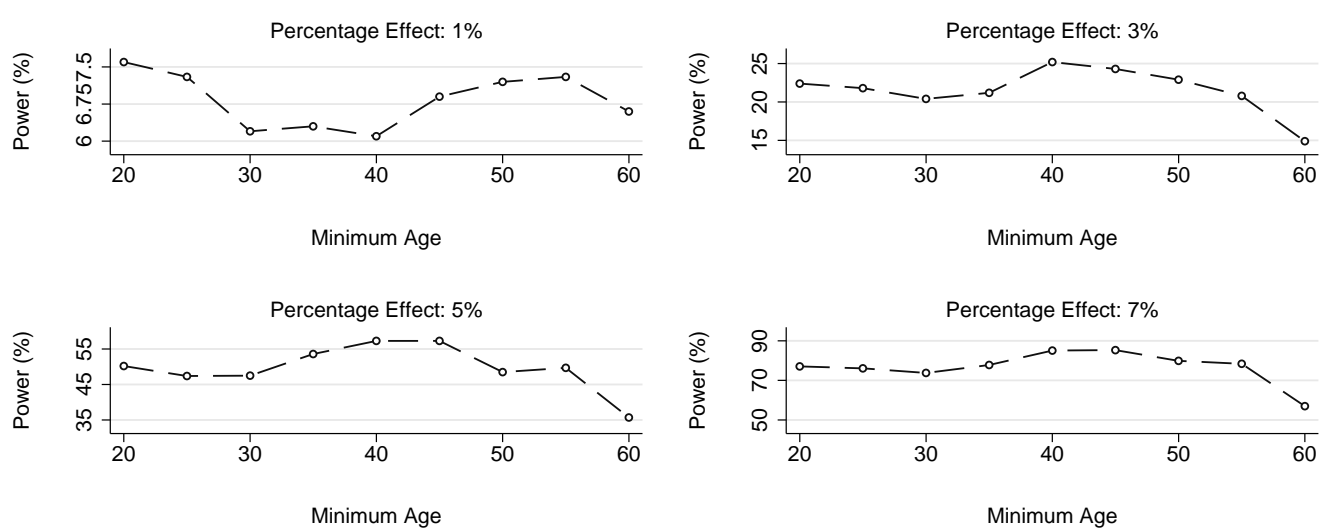

Uninsured Complier Scalar: 3
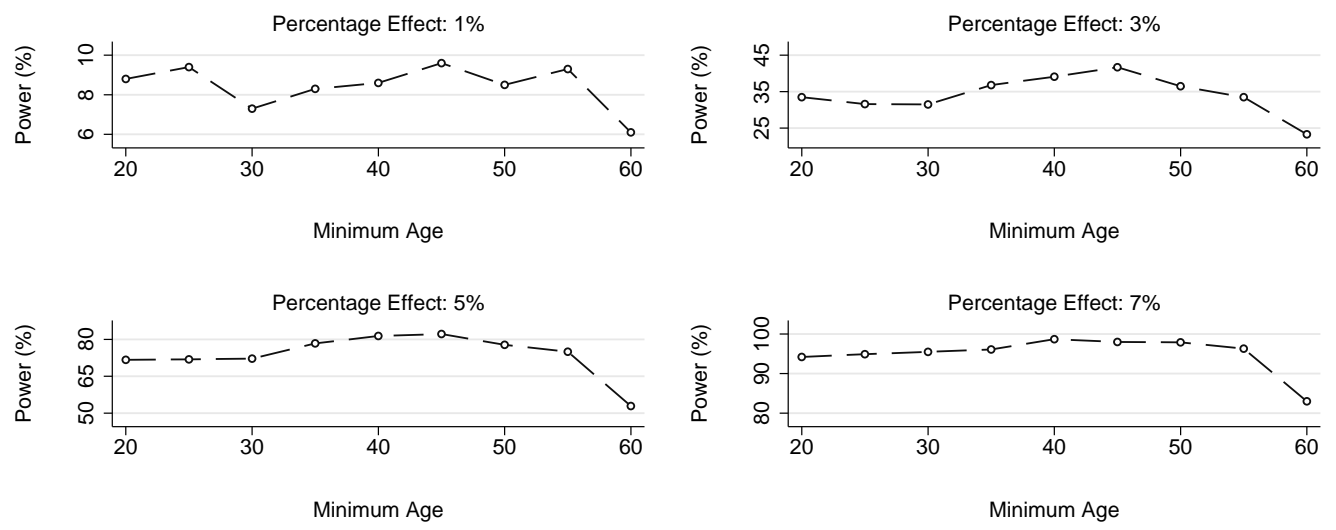

Uninsured Complier Scalar: 4

Notes: The figure displays the probability of detecting a difference between treatment and control group mortality at a $5 \%$ level of significance, for varying age ranges and effect sizes. Results are based on simulations with $\mathrm{N}=1000$ random draws of treatment and control populations. Within a figure, the $\mathrm{x}$-axis reflects the minimum age included in the analysis; the maximum age is held fixed at 64 . The effect of the intervention on coverage for each age range comes from comparing average months of 2017-18 coverage in the treatment and control groups, for individuals with the specified ages that did not have coverage in each month of 2016. The effect of coverage on mortality is alternatively assumed to be a reduction in baseline complier mortality of 1,3,5, or 7\%. Baseline mortality is estimated from populationlevel mortality rates for 2016 from the Social Security Death Index among individuals alive at the end of 2015 , aggregated into 5 -year age bins. The mortality rate for uninsured compliers, absent insurance is alternatively assumed to be 2,3 , or 4 times the average mortality rate for the general population. 
Figure A.4: Effect of Intervention on Rate of New Deaths

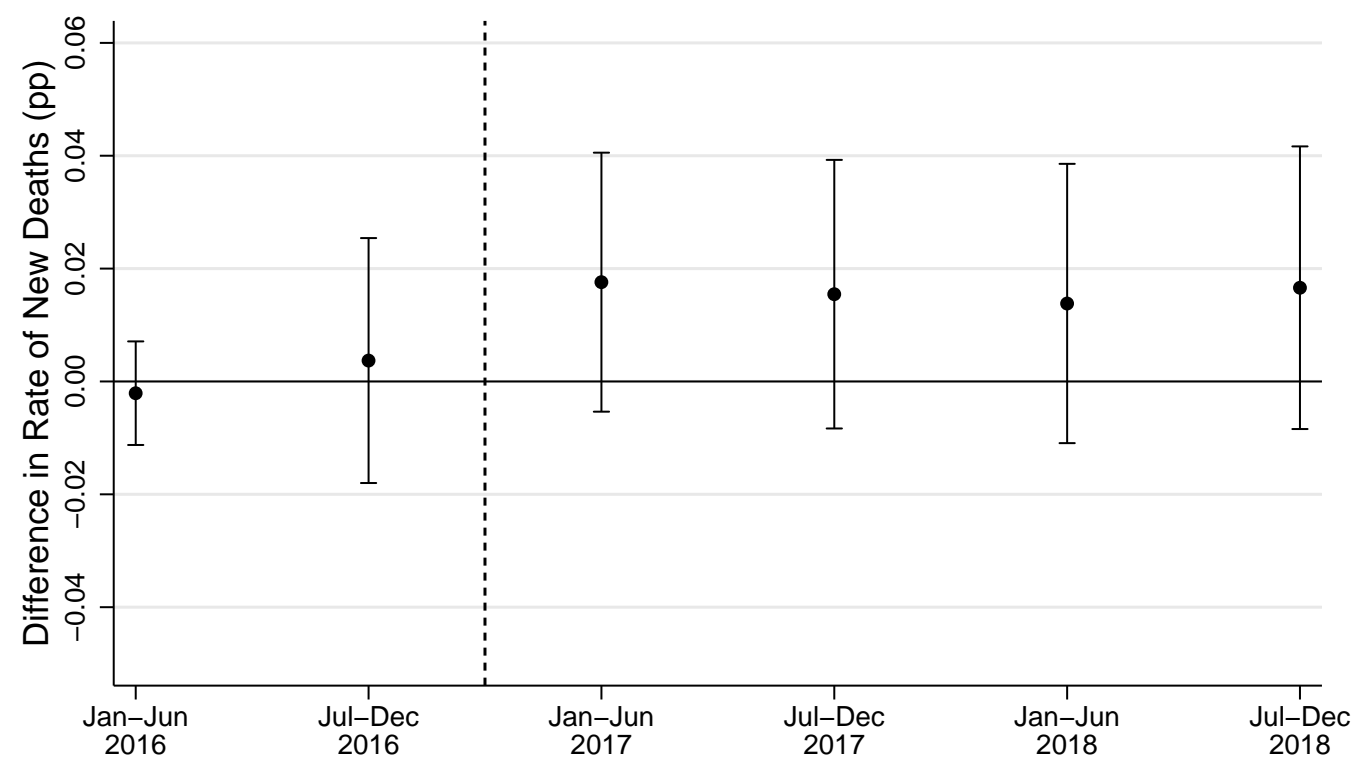

Notes: The figure displays the difference in the share of new deaths between the control

and treatment groups during the six-month interval extending through the end of the specified month. Units are percentage points $(0-100)$. Brackets denote the $95 \%$ confidence interval based on standard errors that are clustered by household. The analysis is limited to individuals between the ages of 45-64 at the start of 2017 and excludes individuals with full coverage in January through November of 2016.

Figure A.5: Permutation Test

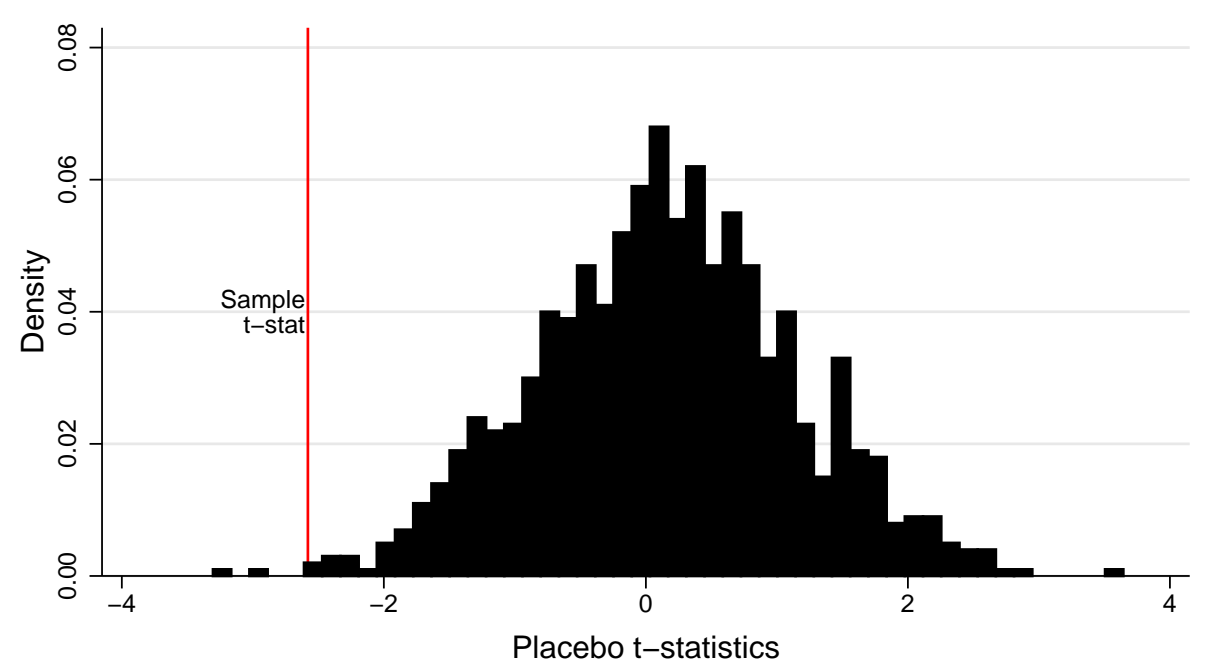

Notes: The figure plots the distribution of treatment effect t-statistics generated

from 1000 random reassignments of the treatment variable across the households in the sample population. The estimated t-statistics correspond to the specification reported in Column 1 of Table 7. The vertical line denotes the $t$-statistic estimated using the actual sample population. 
Figure A.6: Cumulative Distribution of Months of 2017-18 Coverage

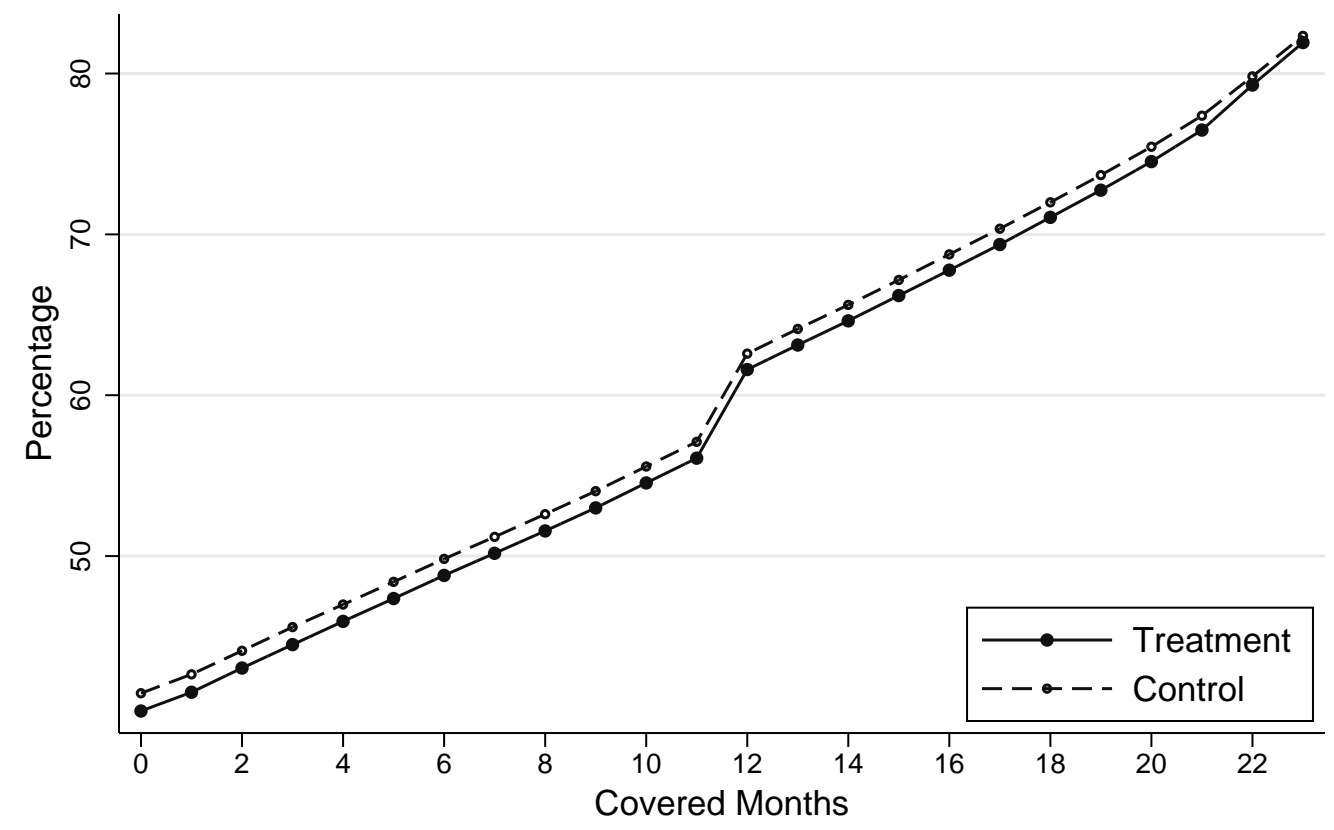

Notes: The figure displays the cumulative distribution function of the number of months of coverage during 2017 and 2018. The figure excludes individuals with full coverage in January through November of 2016. 
Figure A.7: Coverage CDF by Demographic Subgroup

Men

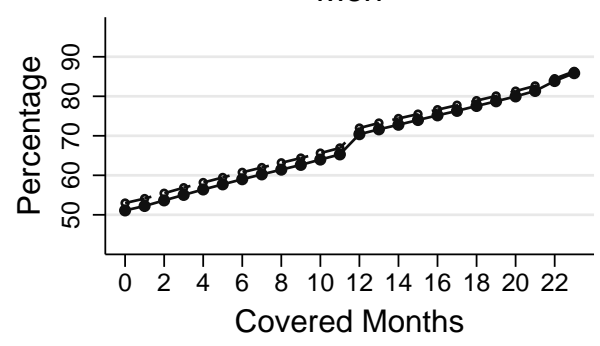

Married

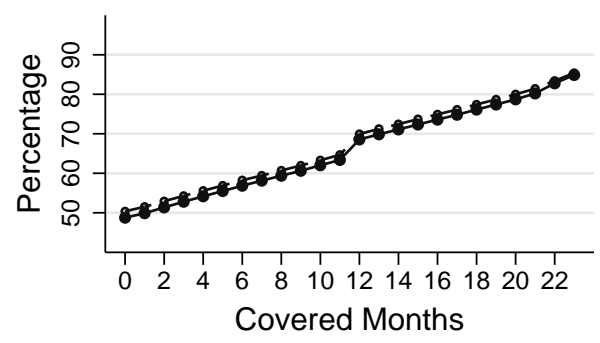

High Income

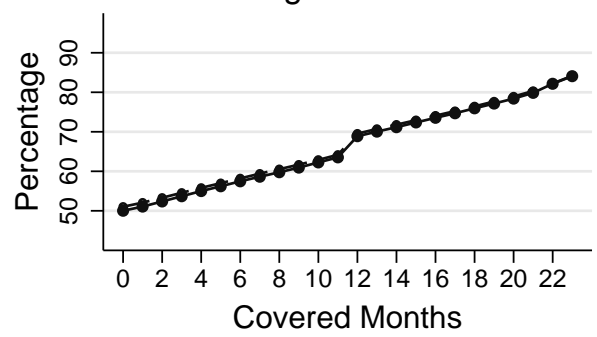

Women

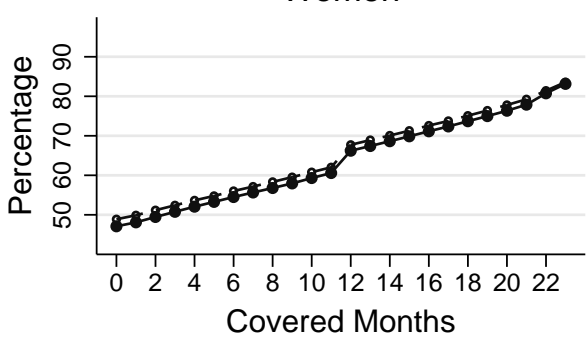

Not Married

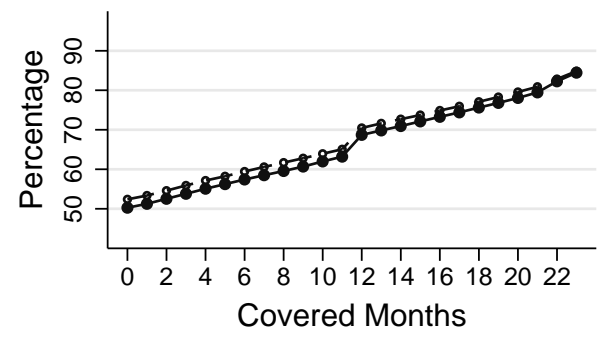

Low Income

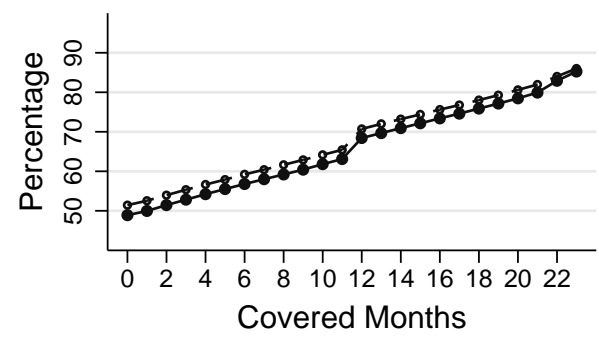

Notes: Each figure displays the cumulative distribution function of months of coverage in 2017 and 2018. High income is defined as having a ratio of household income to the federal poverty line above the sample median. The figure is limited to individuals between the ages ages of 45-64 at the start of 2017 and excludes those with full coverage in January through November of 2016. 
Figure A.8: Distribution of New Coverage Months Induced by the Intervention

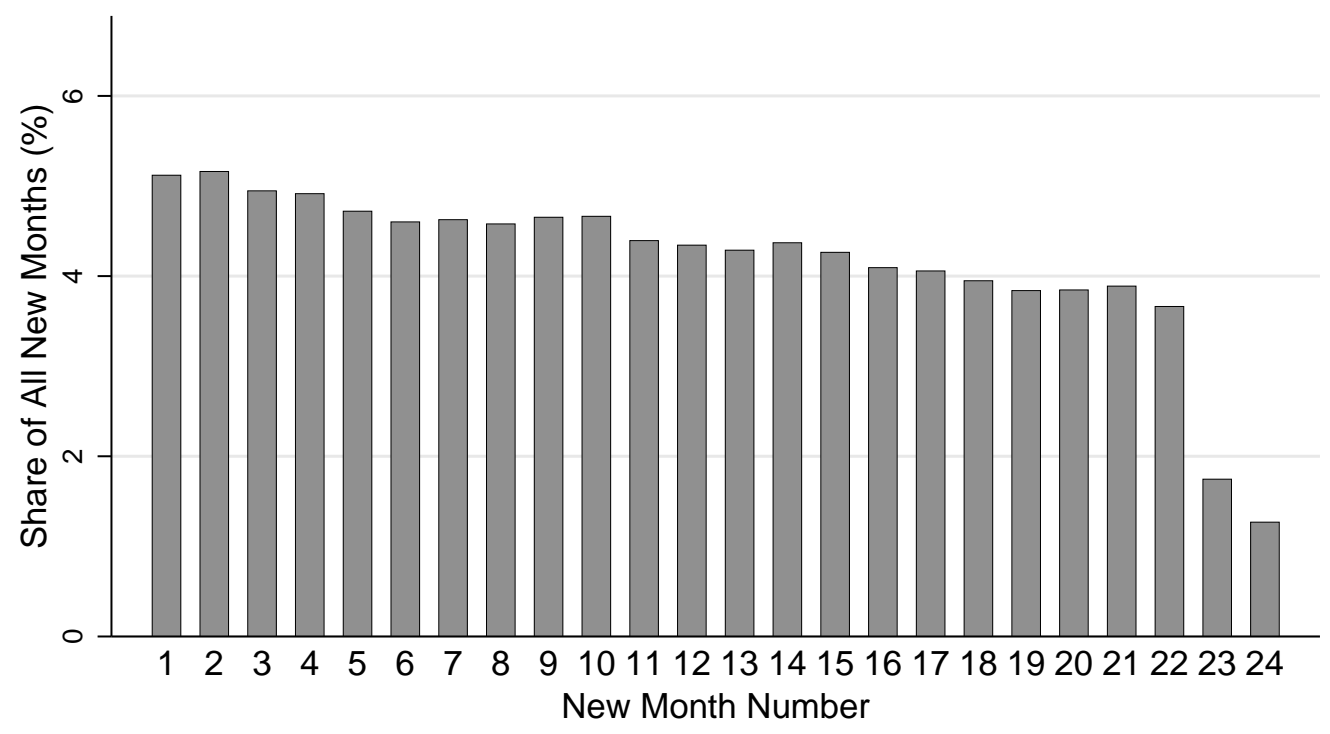

Notes: The figure displays the share of additional coverage months induced by the intervention that represent an individual's specified month of coverage. For example, the bar for month 3 indicates that approximately $5 \%$ of the additional months induced by the intervention represented the individual's third month of coverage during 2017. The figure is limited to individuals between the ages of 45-64 at the start of 2017 and excludes individuals with full coverage in January through November of 2016.

Figure A.9: Effect of Intervention on Number of Covered Months Among 45-64 Year-Olds

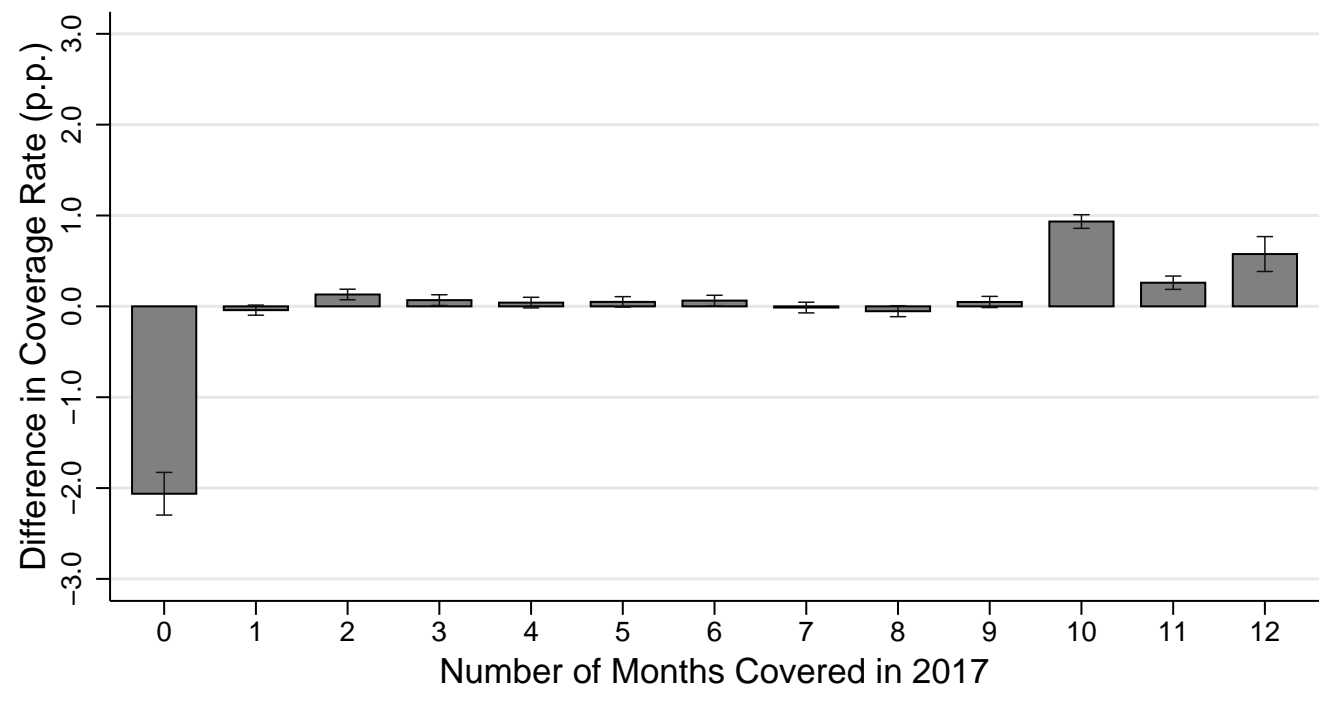

Notes: The figure denotes the difference between the treatment and control groups in the fraction of individuals who enroll in the specified number of months of 2017 coverage. The vertical axis units are percentage points $(0-100)$. Positive values indicate more individuals were enrolled in the specified number of months of coverage in the treatment group relative to the control group. The analysis includes 45-64 year olds and excludes individuals with full coverage in January through November of 2016 . Brackets denote the $95 \%$ confidence interval based on standard errors that are clustered by household. 
Table A.1: Sample Allocation across Treatment Groups

\begin{tabular}{|c|c|c|c|}
\hline & (1) & $(2)$ & $(3)$ \\
\hline & Individuals & Households & Share \\
\hline Overall & $8,897,821$ & $4,526,675$ & 1.00 \\
\hline Treatment & $7,651,401$ & $3,892,807$ & 0.86 \\
\hline Control & $1,246,420$ & 633,868 & 0.14 \\
\hline \multicolumn{4}{|l|}{ Treatment arm } \\
\hline Base & $2,020,465$ & $1,027,859$ & 0.23 \\
\hline Early & $1,576,560$ & 801,913 & 0.18 \\
\hline Non-Personalized & $2,033,077$ & $1,034,304$ & 0.23 \\
\hline Exemption info & $2,021,299$ & $1,028,731$ & 0.23 \\
\hline \multicolumn{4}{|l|}{ Language } \\
\hline English only & $3,819,261$ & $1,943,194$ & 0.43 \\
\hline English + Spanish & $3,832,140$ & $1,949,613$ & 0.43 \\
\hline
\end{tabular}

Notes: The table contains counts by treatment group assignment. The base treatment was personalized, did not include information about exemptions, and was sent during the January 2017 mailing. The shares reported in column 3 are calculated at the household-level. Households correspond to the individuals listed on a tax return. 
Table A.2: Effect of Intervention by 2015 and 2016 Coverage

\begin{tabular}{lcccc}
\hline & $(1)$ & $(2)$ & $(3)$ & $(4)$ \\
\cline { 2 - 5 } Full 2015 Coverage: & Yes & Yes & No & No \\
Full 2016 Coverage: & Yes & No & Yes & No \\
\hline \hline Treated & 0.063 & 0.951 & 0.096 & 1.375 \\
& $(0.038)$ & $(0.253)$ & $(0.054)$ & $(0.080)$ \\
\hline Control mean & 97.342 & 71.142 & 95.634 & 45.746 \\
Observations & $2,156,674$ & 362,371 & $1,652,814$ & $4,721,794$ \\
\hline
\end{tabular}

Notes: Outcome indicates any 2017 coverage. Units are percentage points (0-100). Full 2015 coverage indicates coverage for all months of 2015. Full 2016 coverage indicates coverage for the first 11 months of 2016. Standard errors, reported in parentheses, are clustered by household.

Table A.3: Medicaid Coverage Effect by Income and Expansion State Status

\begin{tabular}{lcccc}
\hline & $(1)$ & $(2)$ & $(3)$ & $(4)$ \\
\cline { 2 - 5 } & \multicolumn{4}{c}{ Income/FPL Percentage } \\
\cline { 2 - 5 } & $0-100$ & $100-138$ & $138-400$ & $400+$ \\
\hline \hline Treated × Expansion State & 1.152 & 1.913 & 0.611 & 0.193 \\
Treated × Non-Expansion State & $-0.262)$ & $(0.299)$ & $(0.109)$ & $(0.140)$ \\
& $(0.225)$ & 0.375 & -0.049 & -0.106 \\
Expansion State & 20.711 & 19.967 & 8.995 & 3.459 \\
& $(0.320)$ & $(0.359)$ & $(0.135)$ & $(0.167)$ \\
\hline Control mean & 23.517 & 17.871 & 9.967 & 3.074 \\
Observations & 879,457 & 638,779 & $2,934,527$ & 616,667 \\
\hline
\end{tabular}

Notes: Outcome indicates one or more month of Medicaid coverage during 2017. Units are percentage points (0-100). Columns limit the sample based on 2016 household income as a percent of the federal poverty line. All columns exclude individuals with full coverage in January through November of 2016. Standard errors reported in parentheses, are clustered by household. 
Table A.4: Exchange Coverage Effect by Income and Expansion State Status

\begin{tabular}{lcccc}
\hline & $(1)$ & $(2)$ & $(3)$ & $(4)$ \\
\cline { 2 - 5 } & \multicolumn{4}{c}{ Income/FPL Percentage } \\
\cline { 2 - 5 } & $0-100$ & $100-138$ & $138-400$ & $400+$ \\
\hline \hline Treated $\times$ Expansion State & 0.588 & 1.027 & 1.081 & 0.487 \\
Treated $\times$ Non-Expansion State & $0.063)$ & $(0.098)$ & $(0.054)$ & $(0.109)$ \\
& $(0.095)$ & $(0.140)$ & $(0.063)$ & $(0.117)$ \\
Expansion State & -1.602 & -2.014 & 0.148 & 0.678 \\
& $(0.104)$ & $(0.155)$ & $(0.076)$ & $(0.147)$ \\
\hline Control mean & 3.142 & 4.508 & 3.761 & 2.625 \\
Observations & 879,457 & 638,779 & $2,934,527$ & 616,667 \\
\hline
\end{tabular}

Notes: Outcome indicates one or more month of Exchange coverage during 2017. Units are percentage points (0-100). Columns limit the sample based on 2016 household income as a percent of the federal poverty line. All columns exclude individuals with full coverage in January through November of 2016. Standard errors reported in parentheses, are clustered by household.

Table A.5: 2018 Coverage Effect by Type of Coverage

\begin{tabular}{lcccccc}
\hline & $(1)$ & $(2)$ & $(3)$ & $(4)$ & $(5)$ & $(6)$ \\
\cline { 2 - 7 } & Exchange & Medicaid & ESI & Off-Exchange & VA & Medicare \\
\hline \hline Treated & 0.556 & 0.187 & 0.134 & 0.039 & 0.019 & 0.023 \\
& $(0.033)$ & $(0.062)$ & $(0.073)$ & $(0.013)$ & $(0.007)$ & $(0.016)$ \\
\hline Control mean & 4.203 & 18.761 & 30.463 & 0.724 & 0.251 & 1.436 \\
Observations & $5,084,165$ & $5,084,165$ & $5,084,165$ & $5,084,165$ & $5,084,165$ & $5,084,165$ \\
\hline Notes: Outcome indicates enrollment in one month or more of the specified coverage during 2018. Units \\
are percentage points (0-100). All columns exclude individuals with full coverage in January through \\
$\begin{array}{l}\text { November of 2016. ESI refers to employer-sponsored coverage. Off-Exchange refers to individual coverage } \\
\text { not purchased through the Exchange. VA refers to coverage provided through the Veterans Administration. }\end{array}$ \\
Standard errors, reported in parentheses, are clustered by household.
\end{tabular}


Table A.6: Distribution of Covered Months by Treatment

\begin{tabular}{|c|c|c|c|c|c|c|c|c|c|c|c|c|c|}
\hline & $(1)$ & $(2)$ & (3) & (4) & $(5)$ & (6) & $(7)$ & $(8)$ & (9) & $(10)$ & (11) & $(12)$ & $(13)$ \\
\hline \multicolumn{14}{|c|}{ Panel A: 2017 Coverage } \\
\hline Months & 0 & 1 & 2 & 3 & 4 & 5 & 6 & 7 & 8 & 9 & 10 & 11 & 12 \\
\hline Control & 52.443 & 1.651 & 1.849 & 1.891 & 1.898 & 1.949 & 2.004 & 2.033 & 2.121 & 2.282 & 2.906 & 2.940 & 24.032 \\
\hline Treatment & 51.100 & 1.608 & 1.920 & 1.941 & 1.920 & 1.957 & 2.017 & 2.019 & 2.122 & 2.306 & 3.379 & 3.116 & 24.597 \\
\hline \multicolumn{14}{|c|}{ Panel B: 2017-18 Coverage } \\
\hline Months & 0 & 1 & 2 & 3 & 4 & 5 & 6 & 7 & 8 & 9 & 10 & 11 & 12 \\
\hline Control & 41.475 & 1.175 & 1.464 & 1.472 & 1.402 & 1.410 & 1.430 & 1.367 & 1.410 & 1.434 & 1.532 & 1.533 & 5.481 \\
\hline Treatment & 40.368 & 1.169 & 1.504 & 1.455 & 1.447 & 1.419 & 1.438 & 1.375 & 1.391 & 1.432 & 1.553 & 1.539 & 5.509 \\
\hline Months & 13 & 14 & 15 & 16 & 17 & 18 & 19 & 20 & 21 & 22 & 23 & 24 & \\
\hline Control & 1.536 & 1.495 & 1.550 & 1.592 & 1.595 & 1.642 & 1.690 & 1.764 & 1.929 & 2.446 & 2.517 & 17.660 & \\
\hline Treatment & 1.526 & 1.503 & 1.571 & 1.577 & 1.597 & 1.689 & 1.688 & 1.780 & 1.958 & 2.801 & 2.640 & 18.075 & \\
\hline
\end{tabular}

Notes: Panel A denotes the share of treatment and control groups with the specified number of months of coverage during 2017.

Panel B denotes the corresponding shares for months of coverage during 2017 and 2018. All columns exclude individuals with full coverage in January through November of 2016.

Table A.7: Effect of Intervention on Mortality - Alternate Age Cutoffs

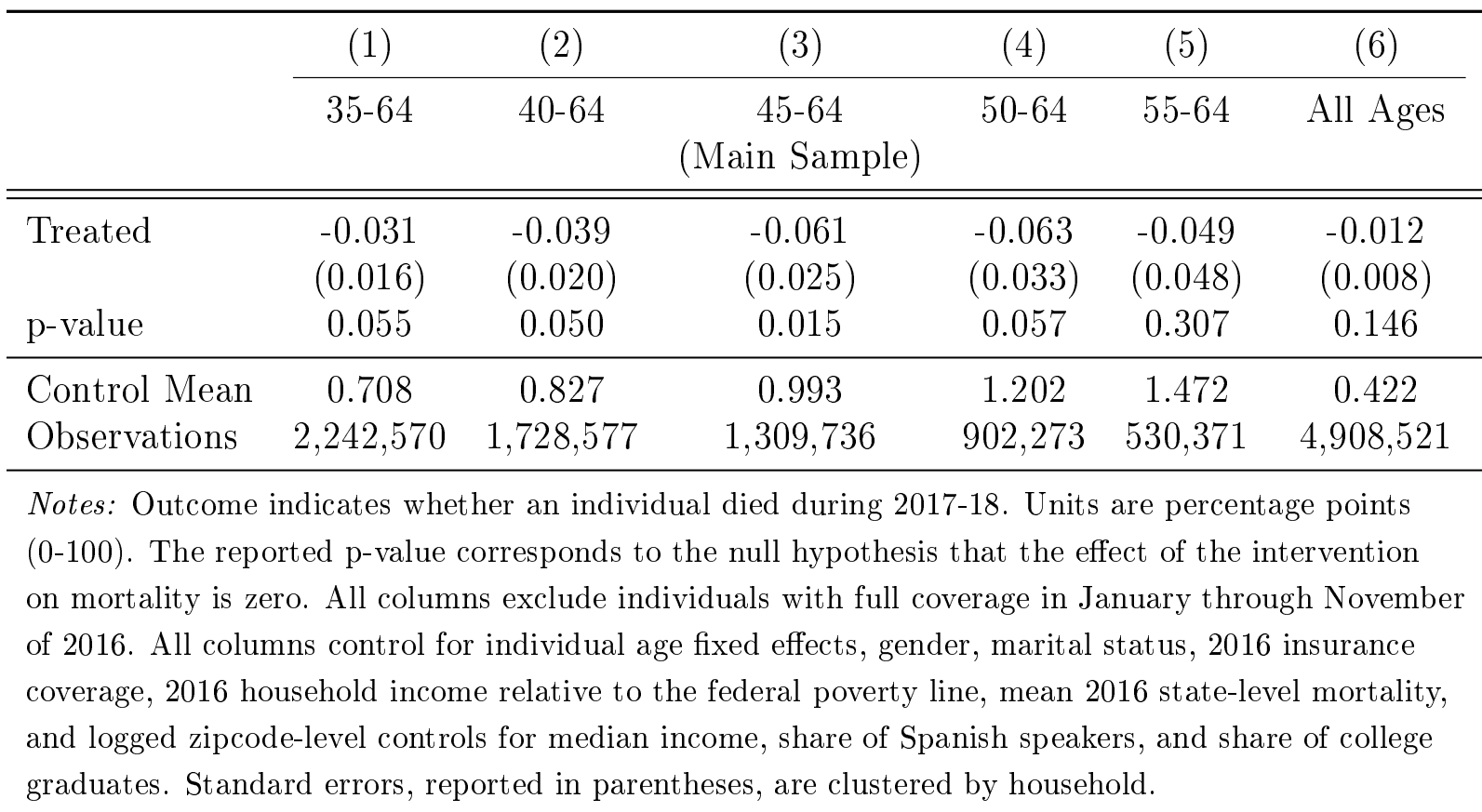


Table A.8: Effect of Intervention on Mortality: No Prior Year Exclusion

\begin{tabular}{lcc}
\hline & $(1)$ & $(2)$ \\
\cline { 2 - 3 } & Mortality & $\begin{array}{c}\text { Mortality } \\
\text { (Controls) }\end{array}$ \\
\hline \hline Treated & -0.045 & -0.044 \\
& $(0.021)$ & $(0.021)$ \\
\hline Control Mean & 1.052 & 1.040 \\
Observations & $2,047,778$ & $1,983,167$ \\
\hline
\end{tabular}

Notes: Outcome indicates whether an individual died during individual died during 2017-18. The analysis includes all individuals between the ages of 45-64, including those with full-year coverage during January through November of 2016. The specification reported in Column 2 controls for individual age fixed effects, gender, marital status, 2016 insurance coverage, 2016 household income relative to the federal poverty line, mean 2016 state-level mortality, and logged zipcode-level controls for median income, share of Spanish speakers, and share of college graduates. Standard errors, reported in parentheses, are clustered by household. 
Table A.9: Effect of Intervention on 2017-18 Mortality (Non-Linear Models)

\begin{tabular}{lccccc}
\hline & $(1)$ & $(2)$ & $(3)$ & $(4)$ & $(5)$ \\
\cline { 2 - 6 } & Logit & Logit & $\begin{array}{c}\text { Cox } \\
\text { Proportional- } \\
\text { Hazard }\end{array}$ & $\begin{array}{c}\text { Cox } \\
\text { Proportional- } \\
\text { Hazard }\end{array}$ & $\begin{array}{c}\text { Log-Rank } \\
\text { Test }\end{array}$ \\
\hline \hline Treated & -6.580 & -6.382 & -6.555 & -6.355 & \\
Marginal Effect & $(2.492)$ & $(2.561)$ & $(2.480)$ & $(2.541)$ & \\
p-value & -0.063 & -0.049 & & & \\
\hline Controls & $0.025)$ & $(0.020)$ & & 0.012 & 0.008 \\
Observations & $1,358,983$ & 0.013 & 0.008 & $\times$ & \\
\hline
\end{tabular}

Notes: Outcome indicates whether an individual died during 2017-18. Units are percentage points (0-100). All columns exclude individuals with full coverage in January through November of 2016 and are limited to individuals between the ages of 45-64 at the start of 2017. Columns 1 and 2 report the results of a logit model. The reported marginal effect is calculated at covariate means. Columns 3 and 4 report the results of a Cox ProportionalHazard model at the month level. In Columns 1-4, the reported p-value corresponds to the null hypothesis that the treatment variable does not enter into the model. Column 5 reports a log-rank test; the p-value corresponds to the null hypothesis of equality between the survival curves for individuals in the treatment and control groups. The specifications reported in Column 2 and 4 control for individual age fixed effects, gender, marital status, 2016 insurance coverage, 2016 household income relative to the federal poverty line, mean 2016 state-level mortality, and logged zipcode-level controls for median income, share of Spanish speakers, and share of college graduates. Standard errors, reported in parentheses, are clustered by household. 
Table A.10: Effect of Intervention on Mortality - Additional Analyses

\begin{tabular}{lcccc}
\hline & $(1)$ & $(2)$ & $(3)$ & $(4)$ \\
\cline { 2 - 5 } & Men & Women & FPL & FPL \\
& & & $\leq 138$ & $>138$ \\
\hline \hline Treated & -0.052 & -0.080 & -0.032 & -0.066 \\
& $(0.035)$ & $(0.032)$ & $(0.055)$ & $(0.027)$ \\
\hline Control mean & 1.204 & 0.737 & 1.203 & 0.929 \\
Observations & 783,582 & 575,199 & 325,270 & $1,016,402$ \\
\hline
\end{tabular}

Notes: Outcome indicates whether an individual died during 2017-18. Units are percentage points (0-100). Column 1 limits sample to men. Column 2 limits the sample to women.

Column 3 limits the sample to individuals whose household income as a percent of the federal poverty line is less than $138 \%$. Column 4 limits the sample to individuals whose household income as a percent of the federal poverty line exceeds $138 \%$. All columns are limited to individuals between the ages of 45-64 and exclude individuals with full coverage in January through November of 2016. Standard errors, reported in parentheses, are clustered by household. 
Table A.11: Comparison to Estimated Mortality Effects in Prior Research

\begin{tabular}{lcccc}
\hline & $(1)$ & $(2)$ & $(3)$ & $(4)$ \\
\cline { 2 - 5 } & Oregon & $\begin{array}{c}\text { Oregon } \\
\text { (Age-Weighted) }\end{array}$ & $\begin{array}{c}\text { Miller et al. } \\
(2019)\end{array}$ & $\begin{array}{c}\text { ACA Penalty } \\
\text { (This Study) }\end{array}$ \\
\hline \hline Intent-to-Treat & -0.106 & -0.170 & -0.208 & -0.061 \\
First-Stage & $(0.160)$ & $(0.199)$ & & $(0.025)$ \\
Average Causal Response & 2.726 & 2.728 & 1.092 & 0.358 \\
& $-0.187)$ & $(0.194)$ & & $(0.026)$ \\
Overlapping CI & $(0.039)$ & -0.041 & -0.190 & -0.166 \\
\hline \hline
\end{tabular}

Notes: The table presents estimates derived from the Oregon health insurance study (Columns 1 and 2), Miller et al. (2019) (Column 3), and our study (Column 4). The Oregon results are calculated from the public-use replication data, downloaded from https://www.nber.org/oregon/4.data.html.

We use the $20 \%$ subsample with survey data on coverage months, along with the corresponding survey weights. Column 2 adjusts the Oregon survey weights to reflect the age distribution of our mortality analysis sample. The standard errors reported in Columns 1 and 2 are clustered by household. The Miller et al. results are calculated from estimates reported in the draft dated July 10, 2019. The coverage and mortality effect estimates are calculated from their Table 1 (Columns 3 and 4) and reflect the event-study coefficients corresponding to Year 0 and Year 1 (post-expansion). We do not calculate standard errors or confidence intervals for the Miller et al. analysis because we lack the required microdata. The results from our study are drawn from the specifications with control variables.

The "Intent-to-Treat" row presents the intent-to-treat estimate of the intervention on 1.5-yr mortality (Columns 1 and 2) and 2-yr mortality (Column 3 and 4). The units are percentage points (0-100). The "First-Stage" row presents the effect of the intervention on months of coverage enrolled in during the first year post-intervention (Columns 1 and 2) and during the first 2 years post-intervention (Column 3 and 4). For Oregon, the first stage is calculated using survey data on the number of coverage months enrolled in by the treatment and control groups. For the Miller et al. study, the first stage is calculated from the change in the share of uninsured individuals, under the assumption that each individual who obtains coverage because of the treatment does so for each month during the year. The "Average Causal Response" row presents the average causal response of coverage on mortality, and is calculated by dividing the intent-to-treat by the first stage. Units are percentage points (0-100). For the Oregon results, the ITT is first scaled by $12 / 18$ before dividing by the first stage so that both the ITT and first stage reflect a 12-month period. The "Overlapping CI" row presents the ACR values that are included in both our estimated confidence interval and the confidence interval associated with the Oregon ACR estimate. 


\section{Appendix: Identifying Complier Baseline Mortality}

This appendix section formalizes and proves the claim made in section 5.2 that the baseline mortality among individuals who respond to the intervention can be identified when the first-stage effect of the intervention on coverage is limited to the extensive margin. The result extends a similar proposition from Abadie (2002) to the case in which treatment is multi-valued.

Let $Z_{i} \in\{0,1\}$ indicate whether individual $i$ was assigned to the treatment group. Let $C_{i}(Z) \in\{0,12\}$ denote the months of coverage in which $i$ would enroll during 2017 if assigned to treatment group $Z$. Let $Y_{i}(C) \in\{0,1\}$ indicate whether $i$ would die during 2017 if $i$ was enrolled in $C$ months of coverage. Our goal is to estimate average mortality during 2017 among individuals who would enroll in additional coverage because of the intervention, in the state of the world in which they enroll in zero months of 2017 coverage, i.e., $E\left[Y_{i}(0) \mid C_{i}(1)>C_{i}(0)\right]$.

Claim: Suppose $\operatorname{Pr}\left(C_{i}(1)>C_{i}(0)>0\right)=0$. Then, in conjunction with the standard IV assumptions described in section 5.2 (monotonicity, exclusion restriction, independence):

$$
E\left[Y_{i}(0) \mid C_{i}(1)>C_{i}(0)\right]=\frac{\bar{Y}(0,0)(1-\bar{C}(0))-\bar{Y}(0,1)(1-\bar{C}(1))}{\bar{C}(1)-\bar{C}(0)}
$$

where $\bar{Y}(c, z)=E\left[Y_{i} \mid C_{i}=c, Z_{i}=z\right]$ and $\bar{C}(z)=\operatorname{Pr}\left(C_{i}>0 \mid Z_{i}=z\right)$.

Proof: First, note that, $\bar{Y}(0,0)=E\left[Y_{i}(0) \mid C_{i}(0)=0, Z_{i}=0\right]=E\left[Y_{i}(0) \mid C_{i}(0)=0\right]$, where the first equality follows from the exclusion restriction and the second follows from the independence assumption. By the law of iterated expectations, we can write this expression as

$$
\begin{aligned}
\bar{Y}(0,0)= & E\left[Y_{i}(0) \mid C_{i}(0)=0, C_{i}(1)=0\right] \operatorname{Pr}\left(C_{i}(1)=0 \mid C_{i}(0)=0\right) \\
& +E\left[Y_{i}(0) \mid C_{i}(0)=0, C_{i}(1)>0\right] \operatorname{Pr}\left(C_{i}(1)>0 \mid C_{i}(0)=0\right)
\end{aligned}
$$

or, using the definition of conditional probability,

$$
\begin{aligned}
\bar{Y}(0,0)= & E\left[Y_{i}(0) \mid C_{i}(0)=0, C_{i}(1)=0\right] \frac{\operatorname{Pr}\left(C_{i}(1)=0, C_{i}(0)=0\right)}{\operatorname{Pr}\left(C_{i}(0)=0\right)} \\
& +E\left[Y_{i}(0) \mid C_{i}(0)=0, C_{i}(1)>0\right] \frac{\operatorname{Pr}\left(C_{i}(1)>0, C_{i}(0)=0\right)}{\operatorname{Pr}\left(C_{i}(0)=0\right)}
\end{aligned}
$$

Next, under monotonicity, $C_{i}(1)=0 \Longrightarrow C_{i}(0)=0$, so $\operatorname{Pr}\left(C_{i}(1)=0, C_{i}(0)=\right.$ $0)=\operatorname{Pr}\left(C_{i}(1)=0\right)=1-\bar{C}(1)$. In addition, monotonicity and the definition of $\bar{C}(Z)$ imply $\bar{C}(0) \equiv \operatorname{Pr}\left(C_{i}(0)>0\right)=\operatorname{Pr}\left(C_{i}(0)>0, C_{i}(1)>0\right)$ and $\bar{C}(1) \equiv \operatorname{Pr}\left(C_{i}(1)>\right.$ $0)=\operatorname{Pr}\left(C_{i}(1)>0, C_{i}(0)=0\right)+\operatorname{Pr}\left(C_{i}(1)>0, C_{i}(0)>0\right)$. Subtracting $\bar{C}(0)$ from $\bar{C}(1)$ therefore yields $\bar{C}(1)-\bar{C}(0)=\operatorname{Pr}\left(C_{i}(1)>0, C_{i}(0)=0\right)$.

Substituting these results into (4) and using the definition of $\bar{C}(Z)$ yields 


$$
\begin{aligned}
& \bar{Y}(0,0)=E\left[Y_{i}(0) \mid C_{i}(0)=0, C_{i}(1)=0\right] \frac{1-\bar{C}(1)}{1-\bar{C}(0)} \\
& +E\left[Y_{i}(0) \mid C_{i}(0)=0, C_{i}(1)>0\right] \frac{\bar{C}(1)-\bar{C}(0)}{1-\bar{C}(0)}
\end{aligned}
$$

Next, note that because $C_{i}(1)=0$ implies $C_{i}(0)=0$ under monotonicity, it follows that $E\left[Y_{i}(0) \mid C_{i}(0)=0, C_{i}(1)=0\right]=E\left[Y_{i}(0) \mid C_{i}(1)=0\right]=E\left[Y_{i} \mid Z_{i}=1, C_{i}=0\right] \equiv$ $\bar{Y}(0,1)$, where the second equality follows from independence and the third equality follows by definition. Substituting this result into (5) and rearranging yields

$$
E\left[Y_{i}(0) \mid C_{i}(0)=0, C_{i}(1)>0\right]=\frac{\bar{Y}(0,0)(1-\bar{C}(0))-\bar{Y}(0,1)(1-\bar{C}(1))}{\bar{C}(1)-\bar{C}(0)}
$$

Finally, using the law of iterated expectations, we can write

$$
\begin{aligned}
E\left[Y_{i}(0) \mid C_{i}(1)>C_{i}(0)\right]= & E\left[Y_{i}(0) \mid C_{i}(1)>C_{i}(0), C_{i}(0)=0\right] \operatorname{Pr}\left(C_{i}(0)=0 \mid C_{i}(1)>C_{i}(0)\right) \\
& +E\left[Y_{i}(0) \mid C_{i}(1)>C_{i}(0), C_{i}(0)>0\right] \operatorname{Pr}\left(C_{i}(0)>0 \mid C_{i}(1)>C_{i}(0)\right) \\
& =E\left[Y_{i}(0) \mid C_{i}(1)>C_{i}(0), C_{i}(0)=0\right] \operatorname{Pr}\left(C_{i}(0)=0 \mid C_{i}(1)>C_{i}(0)\right)
\end{aligned}
$$

where the second equality follows from the assumption that $\operatorname{Pr}\left(C_{i}(1)>C_{i}(0)>0\right)=0$. 